\title{
The Heat Balance of the Western Hemisphere Warm Pool
}

\author{
DAVID B. ENFIELD \\ NOAA/Atlantic Oceanographic and Meteorological Laboratory, Miami, Florida \\ SANG-KI LEE \\ Cooperative Institute for Marine and Atmospheric Studies, University of Miami, Miami, Florida
}

(Manuscript received 1 March 2004, in final form 20 December 2004)

\begin{abstract}
The thermodynamic development of the Western Hemisphere warm pool and its four geographic subregions are analyzed. The subregional warm pools of the eastern North Pacific and equatorial Atlantic are best developed in the boreal spring, while in the Gulf of Mexico and Caribbean, the highest temperatures prevail during the early and late summer, respectively. For the defining isotherms chosen $\left(\geq 27.5^{\circ}, \geq 28.0^{\circ}\right.$, $\left.\geq 28.5^{\circ} \mathrm{C}\right)$ the warm pool depths are similar to the mixed-layer depth $(20-40 \mathrm{~m})$ but are considerably less than the Indo-Pacific warm pool depth (50-60 m). The heat balance of the WHWP subregions is examined through two successive types of analysis: first by considering a changing volume ("bubble") bounded by constant temperature wherein advective fluxes disappear and diffusive fluxes can be estimated as a residual, and second by considering a slab layer of constant dimensions with the bubble diffusion estimates as an additional input and the advective heat flux divergence as a residual output. From this sequential procedure it is possible to disqualify as being physically inconsistent four of seven surface heat flux climatologies: the NCEP-NCAR reanalysis (NCEP1) and the ECMWF 15-yr global reanalysis (ERA-15) because they yield a nonphysical diffusion of heat into the warm pools from their cooler surroundings, and the unconstrained da Silva and Southampton datasets because their estimated diffusion rates are inconsistent with the smaller rates of the better understood Indo-Pacific warm pool when the bubble analysis is applied to both regions. The remaining surface flux datasets of da Silva and Southampton (constrained) and Oberhuber have a much narrower range of slab surface warming $\left(+25 \pm 5 \mathrm{~W} \mathrm{~m}^{-2}\right)$ associated with bubble residual estimates of total diffusion of -5 to $-20 \mathrm{~W} \mathrm{~m}^{-2}\left( \pm 5 \mathrm{~W} \mathrm{~m}^{-2}\right)$ and total advective heat flux divergence of -2 to $-14 \mathrm{~W} \mathrm{~m}^{-2}( \pm 5$ $\mathrm{W} \mathrm{m}^{-2}$ ). The latter are independently confirmed by direct estimates using wind stress data and drifters for the Gulf of Mexico and eastern North Pacific subregions.
\end{abstract}

\section{Introduction}

Unlike the Indo-Pacific warm pool, the Western Hemisphere warm pool (WHWP; Weisberg 1996) undergoes a very large annual variation in its geographic extent and intensity, almost disappearing in the boreal winter while extending from the eastern North Pacific (ENP) into the tropical Atlantic in late summer (Wang and Enfield 2001; Wang and Enfield 2003). Moreover, the interannual variations in its size are comparable with its average extent in summer. Interannually, the largest warm pools occur during the summer following most, but not all El Niño events and are associated with

Corresponding author address: Dr. David B. Enfield, NOAA/ AOML, 4301 Rickenbacker Causeway, Miami, FL 33149.

E-mail: David.Enfield@noaa.gov an anomalously warm tropical North Atlantic to the east (Enfield and Mayer 1997).

The WHWP is an important player in the Walker and Hadley circulations of the Western Hemisphere, replacing the boreal winter convective center over tropical South America as the summer heat source for the Western Hemisphere Tropics. During the months of its maximum development from June through October, the WHWP is a significant moisture source for the easterly low-level flow from the tropical Atlantic into the eastern North Pacific and the central United States (Bosilovich 2002). It seems likely that the largest variations in warm pool size and intensity (warmth) constitute a key factor in predicting boreal summer climate fluctuations in the Western Hemisphere.

The mechanisms for anomalous warm pool growth have not been determined although numerous studies 
have implicated the surface flux anomalies associated with North Atlantic trade wind departures as explaining sea surface temperature extremes in the tropical North Atlantic (e.g., Enfield and Mayer 1997). To fully resolve this question requires a study of the nearsurface heat balance of the warm pool. A simple slab model of the annual mean balance was done by Wang and Enfield (2003) with the total oceanic heat flux divergence as a residual. However, such an approach is highly simplified by the combining of the ENP and Atlantic subregions together, and rendered uncertain by the undetermined ocean fluxes and the wide discrepancies between estimates of the net surface flux of the order of $80 \mathrm{~W} \mathrm{~m}^{-2}$. By considering the annual mean (steady state) heat balance of the western Pacific warm pool volume surrounded by an isothermal surface, Niiler and Stevenson (1982) were able to separate the diffusive ocean flux divergence from that of the advective terms, because the latter sum to zero over the isothermal surface. Toole et al. (2004, henceforth T04) examined the same balance for the Pacific, Atlantic, and Indian Ocean warm pools but with a time-variable heat storage term so as to investigate the temporal behavior of the balance without the uncertainty of advective fluxes. In this paper we apply the T04 approach but with a more detailed focus on the annual cycle of the WHWP and its subregional components and by using multiple hydrothermal and surface flux datasets plus several isothermal surfaces to better estimate the temporal and geographical variations and their uncertainties.

After explaining our data and methods in section 2, in section 3 we describe the terms of the heat equation in more detail and in section 4 we perform a timevariable version of the Niiler and Stevenson (1982) bubble analysis, generating estimates of the diffusion term as a residual. In section 5 we introduce the residual estimates of diffusive flux divergence into a heat balance for fixed slab layers in the four subregions obtaining a residual estimate of the advective heat flux divergence. In section 6 we make direct estimates of the vertical and horizontal advective heat flux divergence for the Gulf of Mexico and ENP regions using the Ekman divergence $\left(f^{-1} \operatorname{curl} \tau\right)$ and surface drifter data, respectively. These are compared to the residual estimates from the slab-layer analysis in section 7, where we also discuss our results generally. Our results and conclusions are summarized in section 8 .

\section{Data and methods}

In what we call a "bubble analysis," we consider the heat balance within a three-dimensional ocean volume bounded by the sea surface $\left(A_{S}\right)$ and an oceanic isothermal surface $\left(A_{T}\right)$. Thus, we estimate all but the rightmost term in the modified heat equation from which heat advection across the isothermal boundary has disappeared

$$
\begin{aligned}
\underbrace{\frac{d}{d t} \iiint \rho c_{p}\left(T-T_{0}\right) d v}_{\mathrm{A}} & =\underbrace{\oiint_{A_{S}} Q_{\mathrm{NET}} d s}_{\mathrm{B}} \\
& -\underbrace{\oiint_{A_{T}} Q_{\mathrm{SWP}} d s}_{\mathrm{C}} \\
& +\underbrace{\oiint_{A_{T}} Q_{\mathrm{DIF}} d s}_{\mathrm{D}}
\end{aligned}
$$

(see T04 for derivation), where $T$ is the water temperature; $T_{0}$ is the bounding temperature; $\rho$ and $c_{p}$ are the density and heat capacity of seawater, respectively; and $Q$ denotes a flux of heat through a surface. Term $A$ is the diabatic change in heat storage, comprised of the total change minus the adiabatic change due to the change in volume. Term $B$ is the net heat flux $\left(\mathrm{Q}_{\mathrm{NET}}\right)$ across the sea surface; term $C$ is the shortwave radiative flux that penetrates through the isothermal surface to the colder water below $\left(Q_{\mathrm{SwP}}\right)$; and term $D$ is the total (horizontal plus vertical) diffusive heat flux $\left(Q_{\mathrm{DIF}}\right)$, which in the bubble analysis is estimated as a residual.

Our analysis strategy is based on two of the greatest strengths of the bubble approach. First, as already noted, the advective contributions to the heat balance are eliminated, ridding us of one of the most uncertain terms in the generalized ocean heat equation. Second, for an enclosed volume surrounded by colder water the diffusive term must be negative (out of the volume), thus providing us with a most valuable constraint on the results. We use this constraint to disqualify two of the surface flux datasets and thus narrow the uncertainty in term B.

To assess the sensitivity of the heat storage term (A) to the ocean thermal analysis, we use two gridded hydrothermal $[T(x, y, z)]$ climatologies: World Ocean Database 2001 (WOD01; Conkright et al. 2002) and the Fleet Numerical Oceanographic Center's (FNOC) Generalized Digital Environmental product (GDEM; Teague et al. 1990). Because these products are based mostly on the same raw hydrographic data, differences reflect the impact of data handling, namely, processing, quality control, interpolation, averaging, gridding, and such. Except in certain summary tables (where results for both are shown), the results shown will be for the WOD01 data. 
TABLE 1 . The $Q_{\mathrm{NET}}$ datasets used in this study, the time periods for the climatologies used, and the original gridding schemes that were interpolated to the WOD01 grid in this paper.

\begin{tabular}{lllc}
\hline \hline ECMWF 15-yr reanalysis & ERA-15 & Jan $1979 \sim$ Dec 1993 & $2.5^{\circ} \times 2.5^{\circ}$ \\
NCEP-NCAR reanalysis & NCEP1 & Jan $1949 \sim$ Nov 2003 & $\sim 2^{\circ} \times 2^{\circ}$ \\
da Silva et al. & DSU, DSC & Jan 1945 Dec 1989 & $1^{\circ} \times 1^{\circ}$ \\
Southampton & SHU, SHC & Jan $1980 \sim$ Dec 1993 & $1^{\circ} \times 1^{\circ}$ \\
Oberhuber & OBH & Jan 1950 Dec 1979 & $2^{\circ} \times 2^{\circ}$ \\
\hline
\end{tabular}

To assess the effect on the analysis of the isotherm depth relative to the stratification-and of the different areas enclosed by the isotherms-we repeat the calculations for three convenient isotherms: $27.5^{\circ}, 28.0^{\circ}$, and $28.5^{\circ} \mathrm{C}$. The ENP and Atlantic portions of the WHWP are dealt with as separate bubbles. At the lowest temperature $\left(27.5^{\circ} \mathrm{C}\right)$ the ENP portion of the warm pool connects to the much larger Indo-Pacific warm pool via the North Equatorial Countercurrent (NECC) along $5^{\circ}-10^{\circ} \mathrm{N}$. This also occurred in the T04 study (which used $27.0^{\circ} \mathrm{C}$ ), preventing that analysis from isolating any conclusions regarding the ENP region. To avoid this problem we have used the WOD01 hydrothermal data and the Pacific drifter data to estimate the zonal advective heat flux through the $120^{\circ} \mathrm{W}$ meridian along the narrow zonal swath of the NECC. The small error introduced by neglecting that flux can be estimated as $Q_{\text {ERR }}=\rho c_{p} M_{X}\left(T_{120}-T_{0}\right) / A$, where $M_{X}$ is the eastward transport bounded by $T_{0}$, and $T_{120}$ is the average temperature of the section through which it flows. For the ENP subregion $\left(T_{0}=27.5^{\circ} \mathrm{C}\right)$ we add this correction to the right-hand side of (1). The bubbles bounded by the $28.0^{\circ}$ and $28.5^{\circ} \mathrm{C}$ isotherms are never joined with the western Pacific and thus do not require this correction.

At certain times of the year, all three isotherms include Atlantic extensions of the volume east of the core warm pool in the Caribbean, especially at the lowest bounding temperature. These extensions sometimes include separated volumes (e.g., off the coast of Brazil); most of them are too small to bias any conclusions about the larger contiguous warm pool. In the late summer, however, there is a large extension spanning the entire tropical North Atlantic to West Africa, while another large region of the equatorial Atlantic including part of the Gulf of Guinea is included as a separate volume that develops in the boreal spring. This volume is included in the Atlantic bubble calculations.

The term subject to the greatest error is the net surface flux (term B), with very large differences between a number of available $Q_{\text {NET }}$ estimations, even though most of them are based on the same source of data [Comprehensive Ocean-Atmosphere Data Set (COADS; Woodruff et al. 1998)]. The surface flux datasets we use here are the da Silva constrained and unconstrained climatologies (DSC and DSU, respectively; da Silva et al. 1994), Oberhuber (OBH; Oberhuber 1988), Southampton unconstrained (SHU; Josey et al. 1998), Southampton constrained (SHC; Grist and Josey 2003), the first National Centers for Environmental Prediction-National Center for Atmospheric Research (NCEP-NCAR) global reanalysis (NCEP1; Kalnay et al. 1996), and the European Centre for MediumRange Weather Forecasts (ECMWF) 15-yr global reanalysis (ERA-15; Gibson et al. 1997). These datasets and the periods for their climatologies, used in this analysis, are summarized in Table 1 . The first five are based on standard marine observations; the last two are atmospheric global circulation model (AGCM) integrations with assimilated historical data. In the constrained versions (DSC, SHC), parameterizations are adjusted so that $Q_{\text {NET }}$ integrates to zero over the World Ocean and is consistent with the oceanic net heat transport convergence between parallels.

According to Fairall et al. (1996) in situ measurements reveal that sensible heat loss over the IndoPacific warm pool is augmented by $2.5-4.5 \mathrm{~W} \mathrm{~m}^{-2}$ due to the cooling effect of rainfall at the wet-bulb temperature, which is lower than the SST. Applying the applicable formula to the Western Hemisphere region, we find that the sensible heat loss due to rainfall is less than $1 \mathrm{~W} \mathrm{~m}^{-2}$ everywhere except in the ENP region where it averages about $2 \mathrm{~W} \mathrm{~m}^{-2}$ during the rainy season (MayNovember). This is less than the uncertainty in the surface flux data and does not affect the conclusions of this paper; hence we have neglected it.

Subsurface shortwave irradiance attenuation is estimated from satellite ocean-color data [Sea-viewing Wide Field-of-view Sensor (SeaWiFS)] using several algorithms, yielding an attenuation coefficient $K_{a}$ that varies spatially and temporally over the WOD01 grid and for all months of the year. The $K_{a}$ estimates are compared to the historical optical water type standards (constants in time and space) set by Jerlov (1976) and the most appropriate algorithm is adopted. The selected time-space variable attenuation coefficient is then applied to the incoming shortwave radiative flux $Q_{\text {SWR }}$ to obtain the estimated shortwave penetration 
(term C), where $Q_{\text {SwR }}$ corresponds to whichever dataset is used for term B.

We compute the slab-layer heat budgets for four subregions of warm pool development having volumes of constant dimensions: the eastern North Pacific (ENP), the Gulf of Mexico (GoM), the Caribbean (CBN), and the equatorial Atlantic (EQA) (Fig. 1). These calculations are done for the 3-month seasons in which the warm pool is best developed in those subregions. The WOD01 hydrothermal data and the unrejected surface flux climatologies are used as in the bubble analysis to estimate terms A, B, and C. The diffusive flux estimates (term D) corresponding to the surface fluxes are input from the bubble analysis, which is also averaged over the same months and regions. Because the slab calculations do not eliminate the advection terms in the heat equation as occurs in the bubble analysis, these are estimated as a collective total in the residual (vertical plus horizontal).

\section{Description of prescribed terms}

\section{a. Heat storage}

The hydrothermal climatologies are subject to uncertainty due to spatially coherent interannual variability as well as incoherent processes affecting the individual profiles, such as heaving motions and diurnal variability. Averaged over each of the four subregions, the number of WOD01 profiles used in a $1^{\circ}$ square varies from 7 to 8 in the ENP to 46 in the GoM per month. The corresponding area-averaged standard errors for the mean isotherm depths range from 2 to $4 \mathrm{~m}$ (largest in the Caribbean) or $5 \%-10 \%$ of the mean isotherm depth. The standard error for the average temperature above the defining isotherms is $\sim 0.1^{\circ} \mathrm{C}$, or about $10 \%-$ $20 \%$ of the mean annual temperature range. It is difficult to say what these numbers mean in terms of the uncertainty in heat storage because we do not know how much of the error variance is incoherent spatially. Incoherent errors will tend to cancel when averaged over large areas. Therefore, the strategy we adopt here is to compare the extent to which two different analyses (WOD01 and GDEM) of the same underlying data differ in the calculations (this section and section 4). Such comparisons will depend partly on the shallow vertical resolution (10 $\mathrm{m}$ for WOD01, 2-5 $\mathrm{m}$ for GDEM) and on the processing and analysis algorithms used.

Figure 2 shows the annual cycle for the $T_{0}=27.5^{\circ} \mathrm{C}$, $28.0^{\circ}$ and $28.5^{\circ} \mathrm{C}$ isotherms used to define the WHWP in this study (WOD01, solid). For comparison, the GDEM version of the $28.0^{\circ} \mathrm{C}$ isotherm is also shown (dotted). The WHWP is insignificant during the winter months (January-February) with only small features in

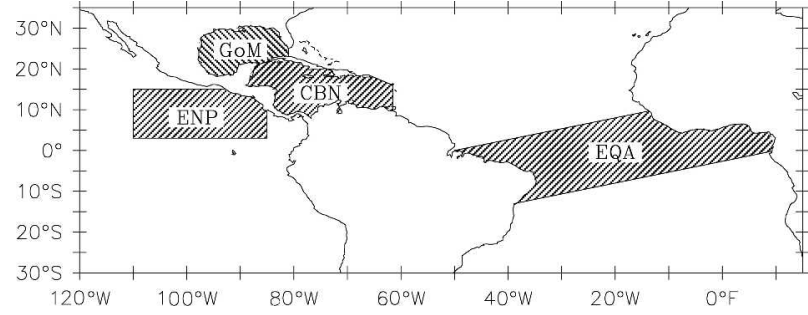

FIG. 1. Subregions of the Western Hemisphere warm pool analyzed in this study: eastern North Pacific (ENP); Gulf of Mexico $(\mathrm{GoM})$; Caribbean (CBN); and the equatorial Atlantic (EQA).

the ENP and EQA regions. The ENP warm pool begins to form off the west coast of Central America in March and attains maximum development in April-May. As the ENP warm pool decreases in size in June and July, the Atlantic warm pool begins to develop in the GoM and is fully developed there in July and August. In August the warm pool expands southward into the $\mathrm{Ca}$ ribbean, while in September and October it is largest and covers all of the Caribbean and much of the tropical North Atlantic. We will refer to the 3-month seasons of April-May-June (AMJ), July-AugustSeptember (JAS), and August-September-October (ASO) as the ENP, GoM, and CBN phases of maximum development, respectively. The EQA region is best developed in March-April-May (MAM), although vestiges of it exist all year-round. These regions and seasons will be specifically analyzed in sections 5 and 6 .

To understand how the various warm-pool-defining volumes relate to their regional shallow stratifications, Table 2 summarizes the 3-month mean isotherm depths $\left(Z_{T}\right)$ and mixed-layer depths [MLD, defined by $\left.T(\mathrm{MLD})=T(0)-0.5^{\circ} \mathrm{C}\right]$ averaged over the appropriate warm pool segments during the phases of maximum development in each region. The calculation for each subregion is restricted to only the grid points within each polygon (Fig. 1) where $T>T_{0}$. For the $T_{0}=$ $27.5^{\circ} \mathrm{C}$ isotherm, this is most or all of the polygon area; for $T_{0}=28.5^{\circ} \mathrm{C}$ it is often only a fraction thereof (cf. Figs. 1 and 2). Even though the areas averaged can be quite different within a given subregion, the mixedlayer depth shows little sensitivity to the area of the defining isotherm, except in the EQA. The mean mixed-layer depth is in general between the $28.0^{\circ}$ and $28.5^{\circ} \mathrm{C}$ depths except in the EQA where it increases with the area of the defining isotherm (i.e., as the proportion of equatorial upwelling area diminishes). Both the warm pool and its associated mixed layer are deepest in the CBN region and shallowest in the ENP and GoM. The rms depth differences between the two climatologies are 1-2 m. Figure 3 shows maps of the WOD01 isotherm depth and MLD for $T_{0}=28.0^{\circ} \mathrm{C}$, 


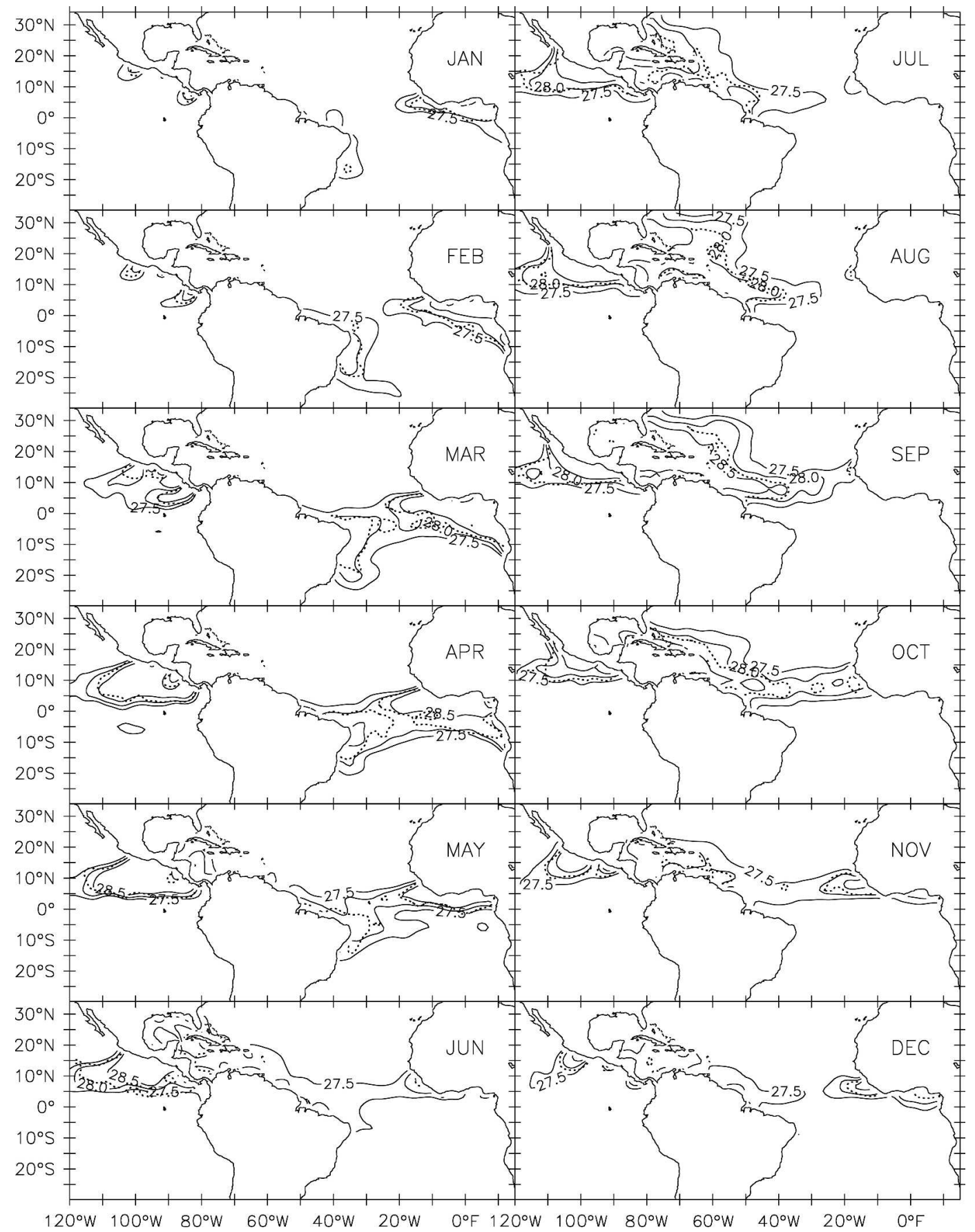

FIG. 2. Distribution of the $27.5^{\circ}, 27.0^{\circ}$, and $28.5^{\circ} \mathrm{C}$ isotherms (solid contours) from the WOD01 hydrothermal climatology. For comparison the $28.0^{\circ} \mathrm{C}$ isotherm is shown for the FNOC's GDEM hydrothermal data (dotted contour).

further illustrating their similarity. Several geographic features stand out. One is the dipole of isotherm depth off Central America in May. This is a remnant of the dynamical forcing of the thermocline by the winter mountain-pass wind jets over the Gulfs of Tehuantepec and Papagayo (McCreary et al. 1989). The deep region south of the Greater Antilles, strongest in September, is clearly the reason for the larger average isotherm depths in the CBN region (Table 2), and it stands in contrast to the shallow region along the north coast of South America where the easterly winds produce persistent coastal upwelling. The deep region is of particu- 
TABLE 2. Three-month mean isotherm depths $\left(Z_{T}\right)$ and mixed-layer depths (MLDs) averaged over the appropriate subregional warm pool segments during the phases of maximum development in each region. The calculation for each subregion is restricted to only the grid points within each polygon (Fig. 1) where $T$ is greater than the temperature defining the warm pool $\left(T_{0}\right)$. Values in the left and right columns are calculated from the $T(z)$ profiles of the WOD01 and GDEM climatologies, respectively.

\begin{tabular}{|c|c|c|c|c|c|c|c|}
\hline \multirow[b]{2}{*}{ Region } & \multirow[b]{2}{*}{ Depth (m) } & \multicolumn{2}{|c|}{$T_{0}=27.5^{\circ} \mathrm{C}$} & \multicolumn{2}{|c|}{$T_{0}=28.0^{\circ} \mathrm{C}$} & \multicolumn{2}{|c|}{$T_{0}=28.5^{\circ} \mathrm{C}$} \\
\hline & & WOD01 & GDEM & WOD01 & GDEM & WOD01 & GDEM \\
\hline \multirow{2}{*}{ ENP (Apr-Jun) } & MLD & 21.7 & 22.3 & 21.6 & 22.4 & 21.0 & 22.1 \\
\hline & $Z_{T}$ & 28.1 & 27.1 & 24.1 & 22.9 & 18.3 & 18.1 \\
\hline \multirow[t]{2}{*}{ GoM (Jul-Sep) } & MLD & 19.9 & 20.9 & 20.0 & 21.0 & 20.1 & 21.5 \\
\hline & $Z_{T}$ & 31.2 & 29.5 & 27.0 & 24.5 & 21.4 & 18.5 \\
\hline \multirow{2}{*}{ CBN (Aug-Oct) } & MLD & 41.3 & 44.1 & 41.8 & 44.9 & 42.4 & 45.7 \\
\hline & $Z_{T}$ & 54.7 & 55.2 & 44.2 & 43.7 & 33.4 & 30.8 \\
\hline \multirow[t]{2}{*}{ EQA (Mar-May) } & MLD & 31.1 & 31.9 & 29.4 & 29.6 & 22.2 & 22.2 \\
\hline & $Z_{T}$ & 33.5 & 32.1 & 24.9 & 24.2 & 17.2 & 17.8 \\
\hline
\end{tabular}

lar importance to Atlantic hurricane forecasters because of its large storm development potential (heat reservoir). Finally, in September the warm pool extends well into the tropical North Atlantic near $10^{\circ} \mathrm{N}$ in association with the north-shifted summer intertropical convergence zone (ITCZ).

Figure 2 shows that the WOD01 and GDEM climatologies are similar for $\mathrm{T}_{0}=28.0^{\circ} \mathrm{C}$, but that differences do occur and the area enclosed is sometimes greater and at other times smaller for one than for the other. From Table 2 we see that the GDEM depths are usually slightly smaller for $\mathrm{T}_{0}$ and slightly larger for MLD. This is mainly due to the finer vertical resolution in GDEM. We have found that the small horizontal and vertical differences in defining volumes between the two hydrothermal analyses do not have a large effect on the heat storage calculations. Therefore, uncertainties in the heat storage term are most likely related to the unknown effects of the uneven distribution of hydrographic data and/or the spatially coherent interannual variability.

\section{b. Net surface flux}

Table 3 summarizes the averages of $Q_{\mathrm{NET}}$ for the same subregions and seasons as shown in Fig. 1 and Table 2, for all seven surface flux climatologies, ranked from left to right according to the average amount of heat absorbed by the ocean annually in the Western Hemisphere Tropics $\left(30^{\circ} \mathrm{S}-30^{\circ} \mathrm{N}\right.$, Africa to $\left.120^{\circ} \mathrm{W}\right)$. Figure 4 shows the distribution of $Q_{\mathrm{NET}}$ for the two surface flux climatologies that comprise the extremes (DSU, ERA-15) and their difference. At one end of the range the DSU and SHU datasets are very close and give the greatest amount of net heat flux into the ocean.

TABLE 3. The $Q_{\text {NET }}$ values from seven heat flux climatologies, averaged within warm pool boundaries (WOD01 isotherms used) for the subregions, as in Table 2 and for the same seasons. The last rows are totals for the entire warm pool and year. Columns are ranked from left to right according to the average amount of heat absorbed by the ocean annually in the Western Hemisphere Tropics $\left(30^{\circ} \mathrm{S}-30^{\circ} \mathrm{N}\right.$, Africa to $\left.120^{\circ} \mathrm{W}\right)$.

\begin{tabular}{|c|c|c|c|c|c|c|c|c|}
\hline Region & $T_{0}$ & SHU & DSU & $\mathrm{OBH}$ & DSC & SHC & NCEP1 & ERA-15 \\
\hline \multirow[t]{3}{*}{ ENP (Apr-Jun) } & 28.5 & 85.4 & 86.3 & 49.7 & 49.6 & 48.0 & 50.8 & 22.1 \\
\hline & 28.0 & 81.9 & 81.6 & 47.2 & 46.1 & 43.3 & 50.2 & 18.6 \\
\hline & 27.5 & 79.3 & 78.6 & 45.4 & 43.4 & 40.4 & 49.7 & 17.9 \\
\hline \multirow{3}{*}{ GoM (Jul-Sep) } & 28.5 & 91.0 & 84.4 & 43.7 & 42.9 & 51.2 & 28.6 & -15.0 \\
\hline & 28.0 & 90.8 & 84.4 & 43.7 & 43.0 & 45.1 & 29.0 & -14.7 \\
\hline & 27.5 & 90.7 & 84.5 & 43.7 & 43.0 & 42.0 & 29.0 & -14.7 \\
\hline \multirow[t]{3}{*}{ CBN (Aug-Oct) } & 28.5 & 73.7 & 69.0 & 23.8 & 29.0 & 6.6 & 6.8 & -21.7 \\
\hline & 28.0 & 73.2 & 70.0 & 22.8 & 30.0 & 12.9 & -0.2 & -19.7 \\
\hline & 27.5 & 73.7 & 70.6 & 23.2 & 30.8 & 13.7 & -0.01 & -18.7 \\
\hline \multirow[t]{3}{*}{ EQA (Mar-May) } & 28.5 & 80.3 & 85.8 & 59.3 & 49.9 & 40.2 & 41.5 & 1.9 \\
\hline & 28.0 & 81.5 & 86.7 & 53.0 & 50.5 & 43.0 & 41.1 & -5.6 \\
\hline & 27.5 & 81.9 & 85.2 & 50.1 & 48.8 & 44.0 & 40.6 & -6.1 \\
\hline \multirow[t]{3}{*}{ Total (Jan-Dec) } & 28.5 & 90.7 & 95.6 & 65.4 & 58.9 & 51.7 & 49.8 & 16.0 \\
\hline & 28.0 & 85.4 & 90.0 & 56.7 & 53.1 & 46.4 & 44.6 & 5.9 \\
\hline & 27.5 & 82.9 & 86.0 & 51.2 & 48.6 & 43.8 & 39.8 & 2.0 \\
\hline
\end{tabular}




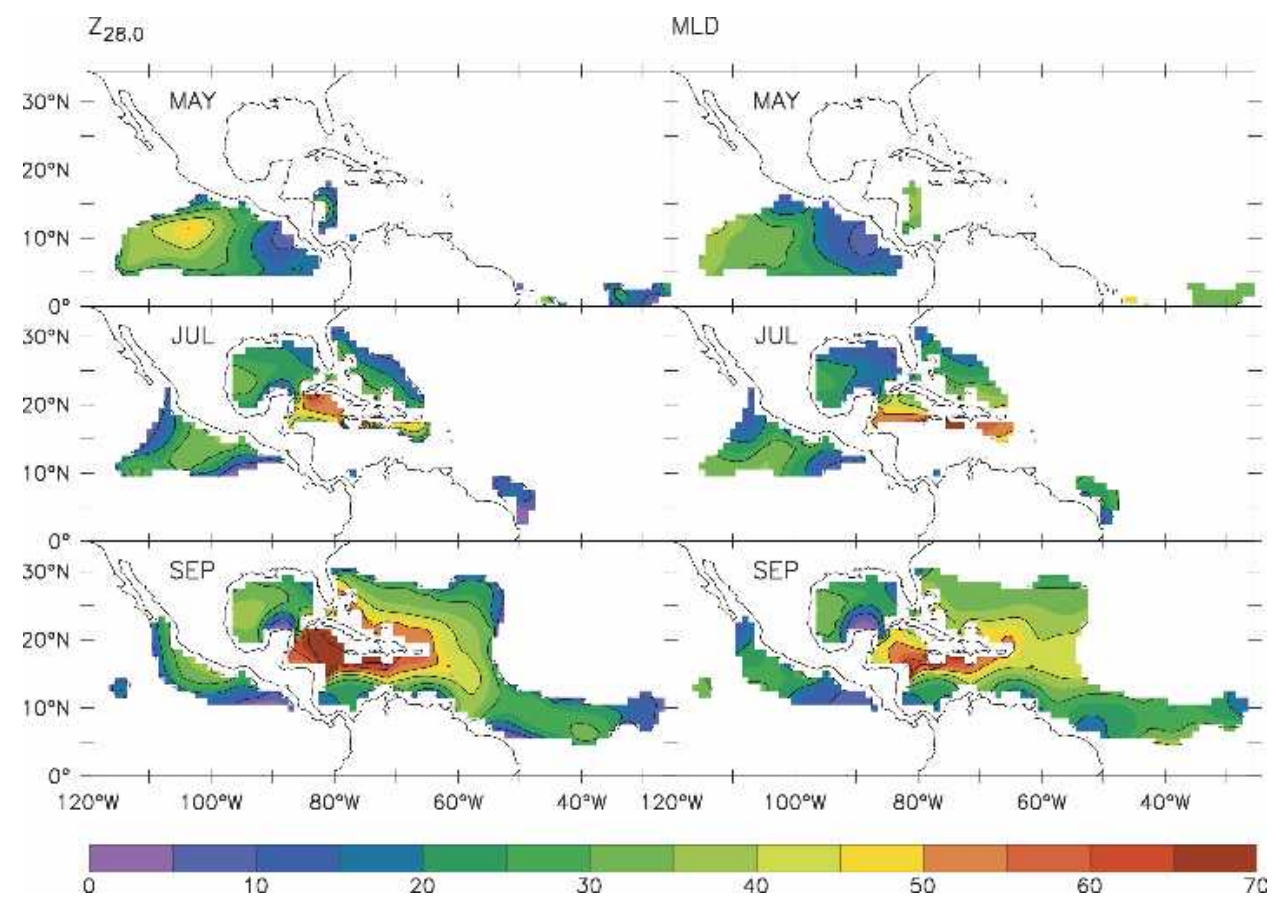

FIG. 3. Map comparisons of the $28.0^{\circ} \mathrm{C}$ isotherm depth against the WOD01 mixed-layer depth for the warm pool months of May, Jul, and Sep.

At the other extreme are the two reanalyses (NCEP1 and ERA-15) with the least absorbed heat. In some regions, such as off Brazil in the South Atlantic and in the subtropical North Atlantic, the differences between extremes are nearly $150 \mathrm{~W} \mathrm{~m}^{-2}$. Ranges of $75-100 \mathrm{~W}$ $\mathrm{m}^{-2}$ are typical over the ENP + EQA, GoM, and CBN regions during their respective periods of maximum development (May, July, September). Averaged over the

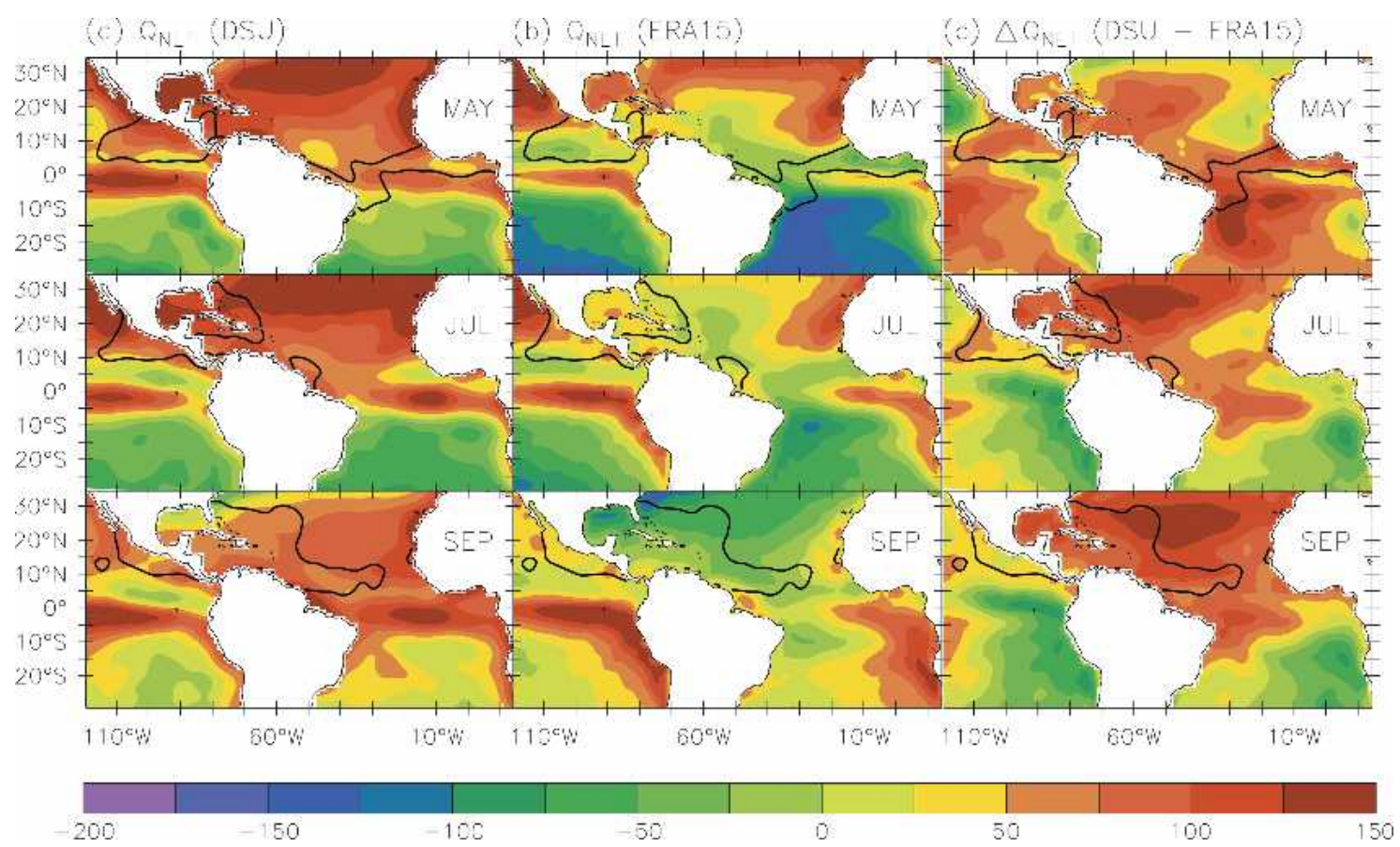

FIG. 4. Map comparisons for the two extremes of the seven surface flux climatologies used in the study: (left) da Silva (unconstrained) and (middle) ERA-15 (ECMWF). (right) The difference distribution. (Units: $\mathrm{W} \mathrm{m}^{-2}$.) 
TABLE 4. (upper tier) Three-month means of the shortwave radiative flux $Q_{\text {SwP }}\left(\mathrm{W} \mathrm{m}^{-2}\right)$ penetrating past $25 \mathrm{~m}$. Each column applies the attenuation coefficient appropriate for a Jerlov water type (constant in space and time) or for a SeaWiFS-derived satellite algorithm (spatially and temporally variable). All calculations are applied to the DSU incoming shortwave radiative flux at each grid point, then averaged over the indicated subregion (Fig. 1 ) and 3-month period. (lower tier) As above, but for the areaaveraged $28.0^{\circ} \mathrm{C}$ isotherm depth (Table 2) within the same subregions and periods. As defined by Jerlov, type I water is the clearest, consistent with subtropical open ocean ("blue") environments, while type III water is most turbid, typical of river outflows and highly productive coastal waters. The subtype IA is closest to but slightly more turbid than type I, while the Jerlov subtype IB is closest to but slightly less turbid than type II.

\begin{tabular}{lcccccccc}
\hline \hline & \multicolumn{3}{c}{ Jerlov water types } & & \multicolumn{3}{c}{ SeaWIFS algorithms } \\
\cline { 2 - 3 } \multicolumn{1}{c}{ Region } & I & II & III & & MOR & K490 & OHL \\
\hline ENP (Apr-Jun) & 34.28 & 26.35 & 18.35 & & 21.36 & 23.40 & 18.07 \\
GoM (Jul-Sep) & 37.78 & 29.04 & 20.23 & & 20.27 & 23.95 & 18.17 \\
CBN (Aug-Oct) & 34.15 & 26.25 & 18.28 & & 17.89 & 20.96 & 15.82 \\
EQA (Mar-May) & 32.84 & 25.24 & 17.58 & & 21.94 & 26.20 & 20.34 \\
ENP (Apr-Jun) & 38.15 & 30.92 & 23.62 & & 26.78 & 27.68 & 24.48 \\
GoM (Jul-Sep) & 34.32 & 26.45 & 18.57 & & 20.24 & 23.62 & 17.8 \\
CBN (Aug-Oct) & 20.14 & 15.15 & 10.51 & & 11.94 & 14.49 & 10.51 \\
EQA (Mar-May) & 36.51 & 29.36 & 22.16 & & 26.55 & 29.9 & 26.48 \\
\hline
\end{tabular}

Western Hemisphere Tropics, the largest contribution to the differences in $Q_{\mathrm{NET}}$ (between climatologies) comes from the incoming shortwave radiation and the next largest from the latent heat flux. For the four subregions, the rms differences between all pairs of climatologies range between 12 and $25 \mathrm{~W} \mathrm{~m}^{-2}$ for latent heat flux to between 29 and $35 \mathrm{~W} \mathrm{~m}^{-2}$ for shortwave radiation.

\section{c. Shortwave penetration}

In Table 4 we compare several different strategies for estimating the radiative flux that penetrates through the bottom of the warm pool $\left(\mathrm{Q}_{\mathrm{SWP}}\right)$. One is to apply the irradiance attenuation coefficient appropriate to one of the Jerlov water types (I, II, or III, constant in time and space) to the incoming shortwave radiation. This is the most common approach adapted in other studies. However, several algorithms now exist for deriving space- and time-variable attenuation coefficients from satellite color imagery, a more precise method for a warm pool boundary that changes with respect to the optical water type distribution. The three satellite algorithms tested here are by Morel (1988), Ohlmann (2003), and McLain et al. (2002, hereafter K490), each of which is computed for the WOD01 grid points, applied to the $Q_{\mathrm{SWR}}$ values at the same grid points, and averaged over the warm pool regions and seasons. Figure 5 shows the distribution of the irradiance attenua-

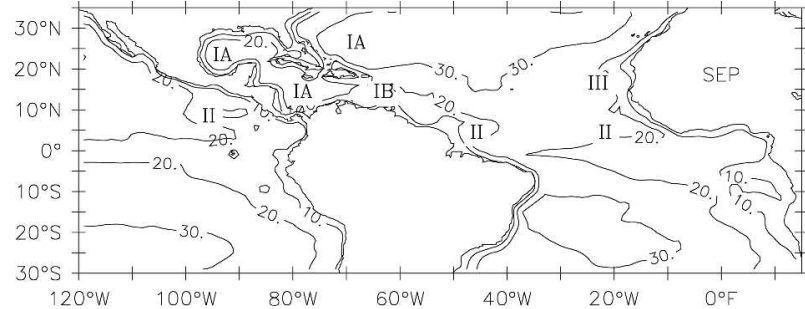

FIG. 5. Contour map of the irradiance attenuation depth (m) derived from color satellite (SeaWiFS) imagery by the K490 method. The Jerlov (1976) optical water types are superimposed (Roman numerals).

tion depth $\left(Z_{A}\right)$ derived from the SeaWiFS attenuation coefficient at $490 \mathrm{~nm}$ (K490), with the Jerlov (1976) water types superimposed.

From Fig. 5 we see that the GoM has the clearest water (IA; $Z_{A}>20 \mathrm{~m}$ ), followed closely by the CBN (IA to IB; $15<Z_{A}<25 \mathrm{~m}$ ), while the ENP and EQA are most turbid (II; $Z_{A}<20 \mathrm{~m}$ ). The K490 algorithm gives patterns that are optimally consistent with the Jerlov water types shown (Fig. 5) and gives shortwave penetrative fluxes that are closest to those inferred from Jerlov's classification (Table 4). If the historical observations are correct, then it appears that among the three satellite methods the K490 estimates are the most reliable. Therefore, in this paper we use the K490 satellite method as being most consistent with direct observations while resolving temporal and spatial variations. For a given depth and incoming shortwave flux, the K490 estimates of the shortwave penetrative flux may have an uncertainty of $\pm 5 \mathrm{~W} \mathrm{~m}^{-2}$. Much larger errors are likely to result from errors in the incoming shortwave radiation.

\section{Bubble analysis}

Figures 6-7 and 8-9, respectively, summarize the bubble-analyzed heat balances for the Pacific and Atlantic portions of the warm pool. Shown in the top panel are the annual cycles of the area-averaged storage rate and sea surface temperature (WOD01); in the middle panel, $Q_{\mathrm{NET}}$ minus $Q_{\mathrm{SWP}}$ for the seven surface flux climatologies; and in the bottom panel the resulting residuals, or estimated total diffusive flux $\left(Q_{\mathrm{DIF}}\right)$ corresponding to the respective surface flux climatologies. For each region the analysis is done separately for the coolest $\left(27.5^{\circ} \mathrm{C}\right.$; Figs. 6,8$)$ and warmest $\left(28.5^{\circ} \mathrm{C}\right.$; Figs. 7 , 9) defining isotherms. In Table 5 the residuals $\left(Q_{\mathrm{DIF}}\right.$ estimates) for both hydrothermal climatologies and all three defining isotherms are shown for the four subregions and their respective seasons of maximum development. The differences between the WOD01 and GDEM climatologies are within $\pm 5 \mathrm{~W} \mathrm{~m}^{-2}$ with no 


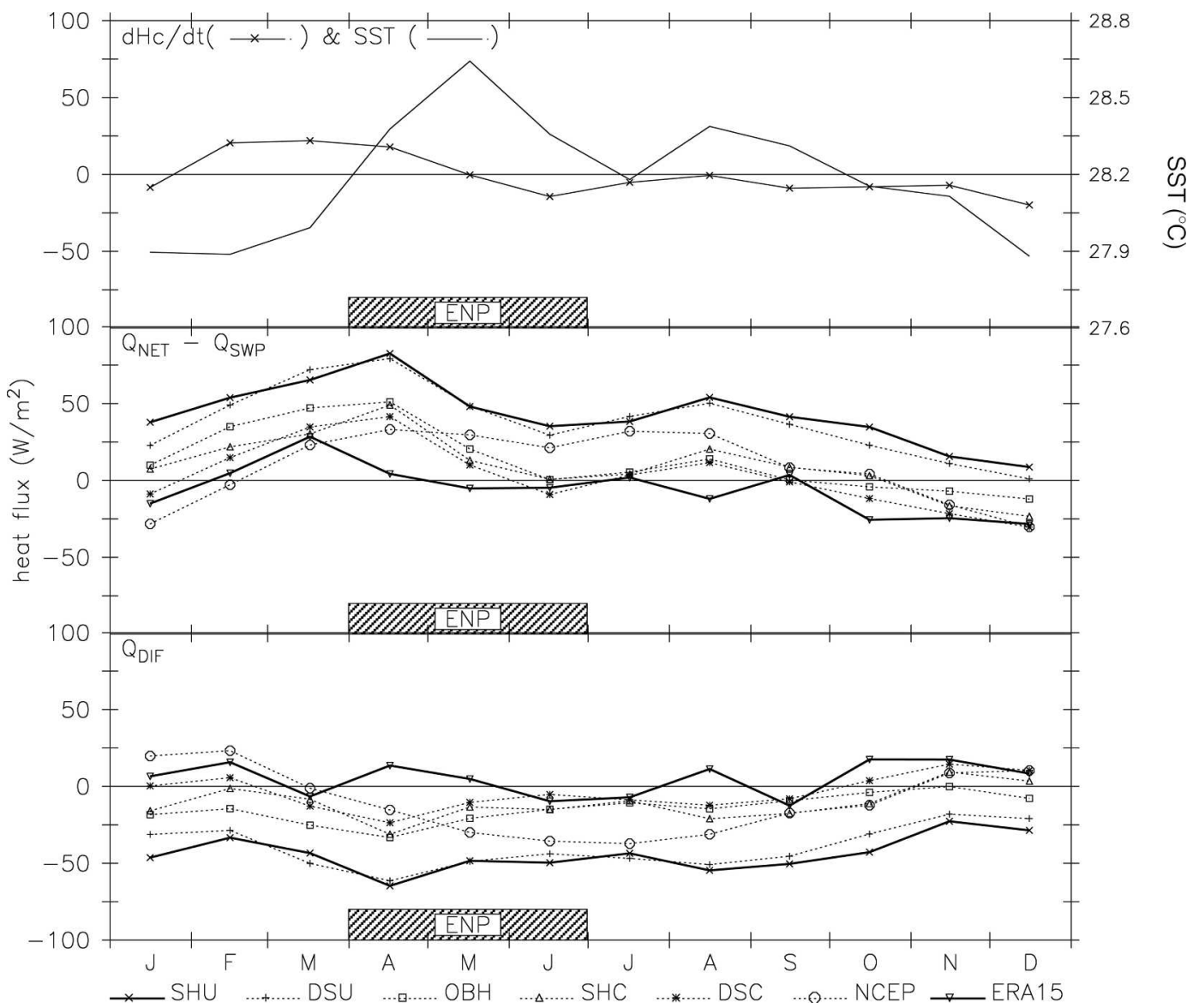

FIG. 6. Annual variation of the bubble heat balance (constant isotherm boundary) for the eastern North Pacific, using the $27.5^{\circ} \mathrm{C}$ isotherm. (top) Sea surface temperature $\left({ }^{\circ} \mathrm{C}\right.$, solid) and heat storage rate $\left(\mathrm{W} \mathrm{m}^{-2}\right.$, solid + symbol) from the WOD01 hydrothermal climatology; (middle) net heating defined as the net surface flux minus the K490-estimated penetrative radiant flux, for seven surface flux climatologies ( $\mathrm{W} \mathrm{m}^{-2}$, legend at bottom); and (bottom) residual estimates of the total diffusive flux divergence corresponding to the datasets used in the middle panel $\left(\mathrm{W} \mathrm{m}^{-2}\right)$. Hatched rectangle indicates the season of maximum development.

clear bias in either direction, and therefore the choice of hydrothermal climatology for defining the warm pool volume has little impact on the resulting balance.

\section{a. Description of the heat balance}

Growth of the warm pool $(d H / d t)$ in the ENP region is restricted to the February-April period, prior to the spring maximum in SST (Fig. 6). The surface heat flux absorbed shows a clear annual cycle for the $27.5^{\circ} \mathrm{C}$ isotherm, which is present year-round. Only a portion of the annual variation can be seen for $28.5^{\circ} \mathrm{C}$, which is only present during the late spring and summer months (Fig. 7). For $27.5^{\circ} \mathrm{C}$ the very similar DSU and SHU climatologies give the greatest absorbed heat, ranging from $25 \mathrm{~W} \mathrm{~m}^{-2}$ or less in October-December to $40-80$ $\mathrm{W} \mathrm{m}{ }^{-2}$ in the February-September time frame. The least heat absorbed is for ERA-15 followed closely by
NCEP1 with a net heat loss in winter. The Oberhuber and the constrained data-based climatologies $(\mathrm{OBH}$, DSC, SHC) fall in the lower half of the range defined by the above extremes. Seasonal changes are similar among the climatologies except for NCEP1, which does not show the strong 3-month decrease after April.

For $27.5^{\circ} \mathrm{C}$ the ENP residual term or estimated total diffusive flux $\left(Q_{\mathrm{DIF}}\right)$ tends to reflect the annual cycle in surface heat gain but is modified by the smaller annual cycle of the storage rate. In November-February $Q_{\text {DIF }}$ varies from a $-25 /-45 \mathrm{~W} \mathrm{~m}^{-2}$ range (DSU, SHU) to $+10 /+25 \mathrm{~W} \mathrm{~m}^{-2}$ (NCEP1, ERA-15), while for MarchOctober it varies from $-50 /-60 \mathrm{Wm}^{-2}$ (DSU, SHU) to $-10 /+20 \mathrm{~W} \mathrm{~m}^{-2}$ (ERA-15). Over the same periods, all the $Q_{\mathrm{NET}}$ datasets (except for NCEP1) yield a similar 15 to $20 \mathrm{~W} \mathrm{~m}^{-2}$ seasonal contrast in $Q_{\mathrm{DIF}}$, which leads us to surmise that the $Q_{\text {DIF }}$ seasonality, though only moderate, is perhaps marginally significant. 


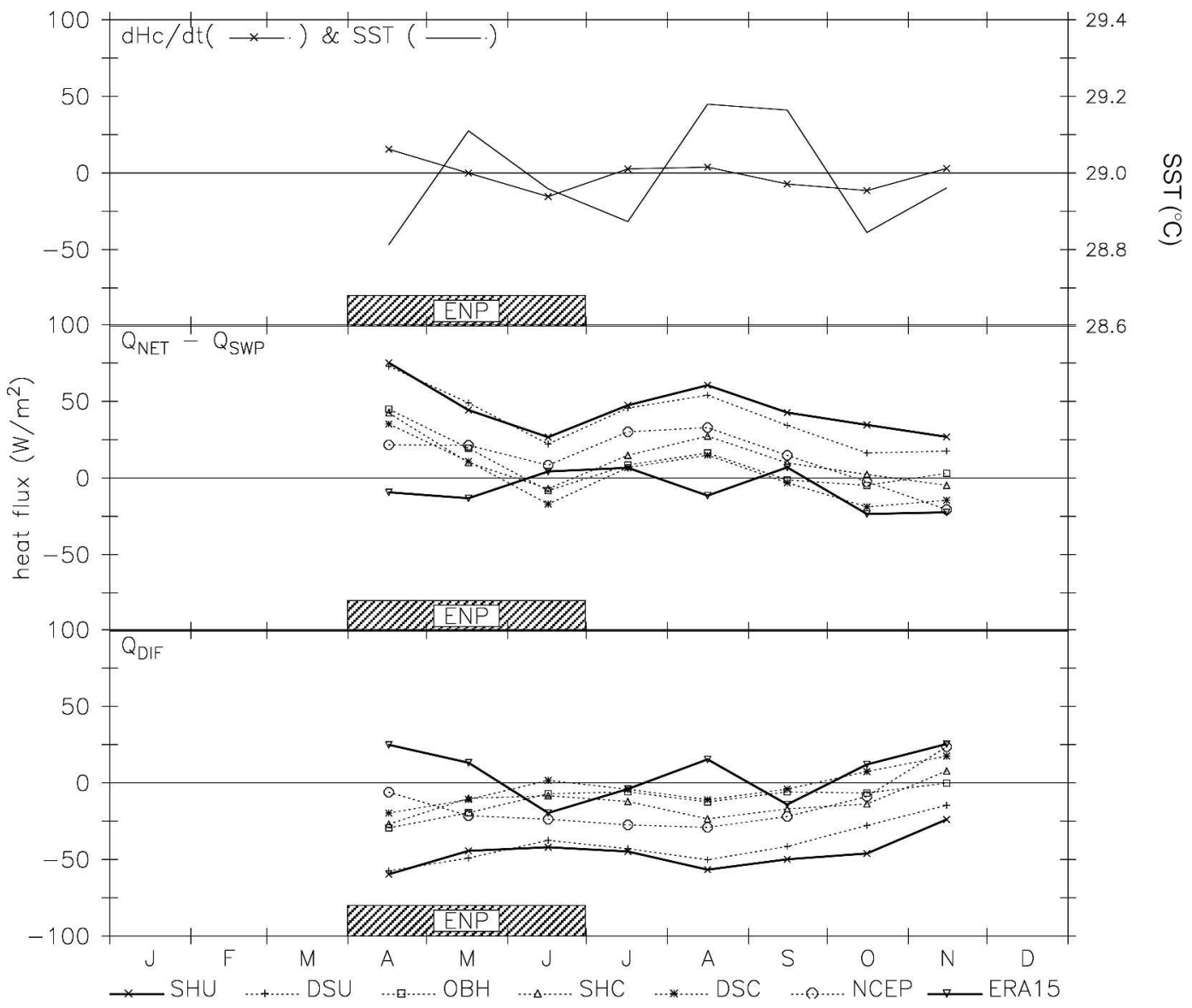

FIG. 7. For the eastern North Pacific as in Fig. 6, but using the $28.5^{\circ} \mathrm{C}$ isotherm instead of $27.5^{\circ} \mathrm{C}$.

The ERA-15 dataset yields unrealistic (nonphysical) or unlikely ENP residuals for $27.5^{\circ} \mathrm{C}$ that are positive (implied diffusive heat gain) for most of the year. Similar, positive residuals occur for NCEP1 during the winter months, but because of the uniquely strong seasonal cycle of NCEP1 $Q_{\mathrm{NET}}$, the summer months have large negative values. The remaining climatologies yield residuals that bracket a physically possible range for $Q_{\text {DIF }}$, from near zero $(\mathrm{OBH}, \mathrm{SHC})$ in winter to more than $50 \mathrm{~W} \mathrm{~m}^{-2}$ of diffusive heat loss from late spring through summer (DSU, SHU). It is difficult to render a similar judgment for $28.5^{\circ} \mathrm{C}$ because most of the winter months are missing. Finally, we note that for the warm pool season the residuals for the $28.5^{\circ}$ and $27.5^{\circ} \mathrm{C}$ isotherms vary within the same ranges, suggesting that the estimate of $Q_{\mathrm{DIF}}$ is insensitive to the warm pool depth (18-28 m), which brackets the mixed-layer depth (21$22 \mathrm{~m}$ ) (Table 2).

In the Atlantic (Fig. 8), the $27.5^{\circ} \mathrm{C}$ results have an unrealistic discontinuity in $Q_{\mathrm{NET}}-Q_{\mathrm{SWP}}$ and $\mathrm{Q}_{\mathrm{DIF}}$ between December and January, and a trend between those extremes during the year. From Fig. 2 we can see the reason for the discontinuity: starting in January and for the first half of the year, the $27.5^{\circ} \mathrm{C}$ Atlantic warm pool is dominated by the Atlantic east of $40^{\circ} \mathrm{W}$ (EQA), while in the latter half of the year through December it is dominated by the western Atlantic, including the GoM and CBN. Hence, rather than being a physically meaningful annual cycle of the heat balance in a given region, the figure represents differences between the two sides of the Atlantic. Even more than for the ENP region, the NCEP1 and ERA-15 climatologies yield a physically inconsistent (positive) range of $Q_{\mathrm{DIF}}$ estimates while the remaining estimates range from $+10 /$ $+15 \mathrm{~W} \mathrm{~m}^{-2}$ (DSC, SHC) to $-55 /-65 \mathrm{~W} \mathrm{~m}^{-2}$ (DSU, SHU) in March-May (eastern Atlantic) and from -10/ $-15 \mathrm{~W} \mathrm{~m}^{-2}$ to $-40 /-50 \mathrm{~W} \mathrm{~m}^{-2}$ in August-October (western Atlantic) (Table 5). Although DSC and SHC give positive residuals in November-December for $27.5^{\circ} \mathrm{C}$ (Fig. 8), these are months when the warm pool areas are small and may yield less stable balances, while the DSC and SHC values during the warm pool seasons give clearly acceptable residuals.

For the $28.5^{\circ} \mathrm{C}$ warm pool (Fig. 9) the eastern and 


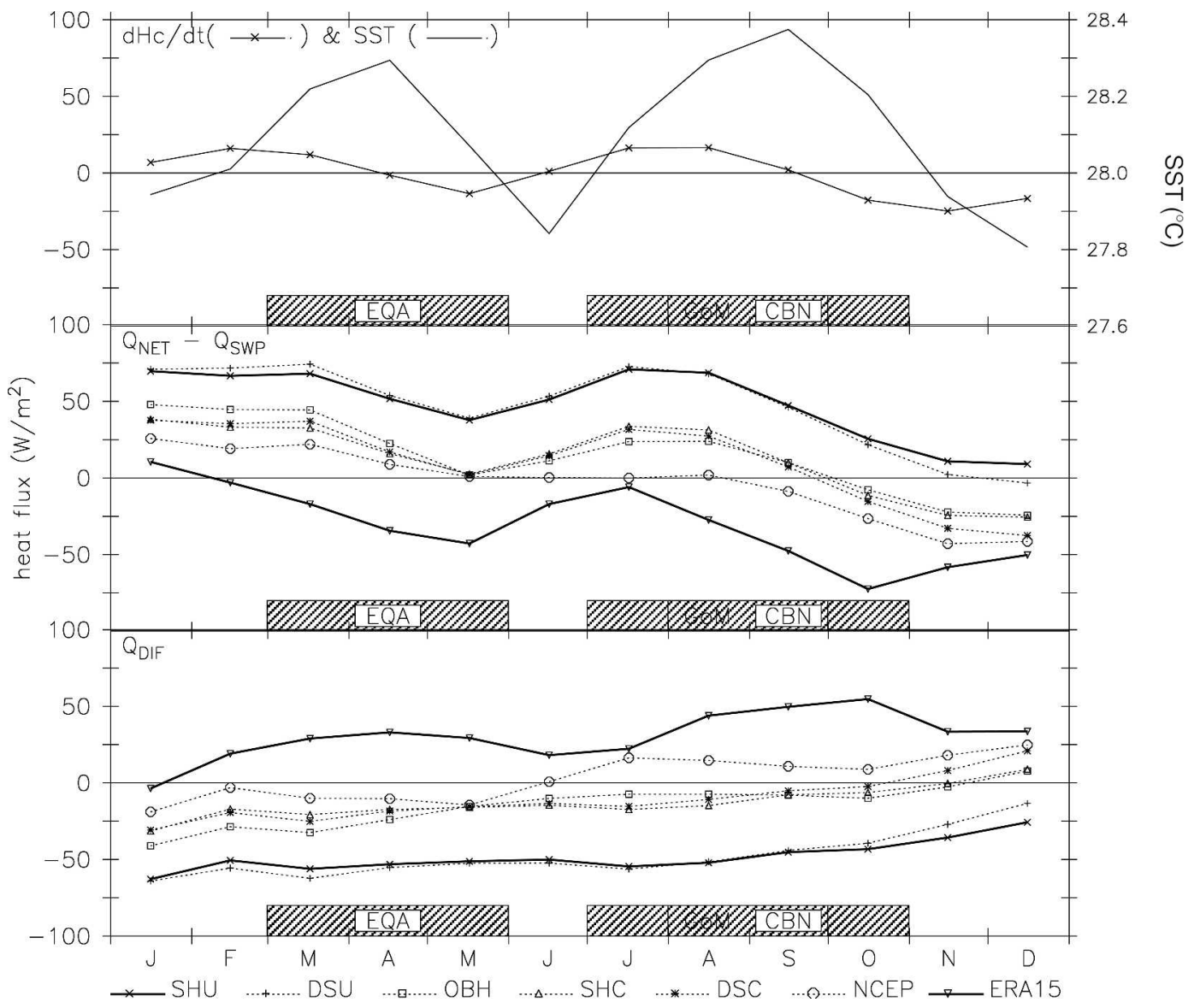

FIG. 8. Using the $27.5^{\circ} \mathrm{C}$ isotherm as in Fig. 6, but for the Atlantic.

western portions of the Atlantic are cleanly separated into the boreal spring and fall months, respectively. As in the Pacific, the residual estimates are insensitive to the defining isotherm. For $28.5^{\circ} \mathrm{C}$ the DSC and SHC climatologies give slightly positive residual values in September and October when the Caribbean is dominant but are quite satisfactory during the ENP and EQA warm pool seasons (Figs. 7, 9).

\section{b. Narrowing the possible balance}

The numerical averages in Table 5 for the subregions and their respective warm pool seasons confirm that the ERA-15 $Q_{\mathrm{NET}}$ gives nonphysical residuals for all regions, while NCEP1 is clearly unrealistic in the IntraAmericas Sea region (GoM, CBN). Some positive residuals occur for DSC and SHC, but they are not large and the averages for the warm pool seasons are acceptable (negative). Hence, we can only disqualify the NCEP1 and ERA-15 surface fluxes as being physically inconsistent in the WHWP region based on sign.

The total diffusion inferred from the remaining five surface flux climatologies falls into two groups: the DSU and SHU climatologies yield much greater diffusive cooling $\left(-35\right.$ to $\left.-55 \mathrm{~W} \mathrm{~m}^{-2}\right)$ than do the $\mathrm{OBH}$, DSC, and SHC climatologies $\left(-5\right.$ to $\left.-25 \mathrm{~W} \mathrm{~m}^{-2}\right)$. To check on which of these two ranges seems most reasonable, we consider the Indo-Pacific warm pool for which far more direct observational evidence exists, including results from the extensive Tropical Ocean Global Atmosphere Coupled Ocean-Atmosphere Response Experiment (TOGA COARE). The consensus of most studies to date is that vertical diffusion there accounts for cooling rates of 0 to $-20 \mathrm{~W} \mathrm{~m}^{-2}$, while horizontal diffusion is generally small west of the central equatorial Pacific (e.g., Ramanathan et al. 1995). However, the Indo-Pacific warm pool is much deeper (50-60 m) than the WHWP, which makes the two regions difficult to compare in this manner. Therefore, we apply our bubble analysis to the Indo-Pacific warm pool west of $120^{\circ} \mathrm{W}$ (subtracting the $120^{\circ} \mathrm{W}$ advective correction described in section 2) and find total diffusive coolings of -45 to $-55 \mathrm{~W} \mathrm{~m}^{-2}$ (SHU, DSU) and -10 to $-20 \mathrm{~W} \mathrm{~m}^{-2}$ (OBH, SHC, DSC). Our results for DSU and SHU are 


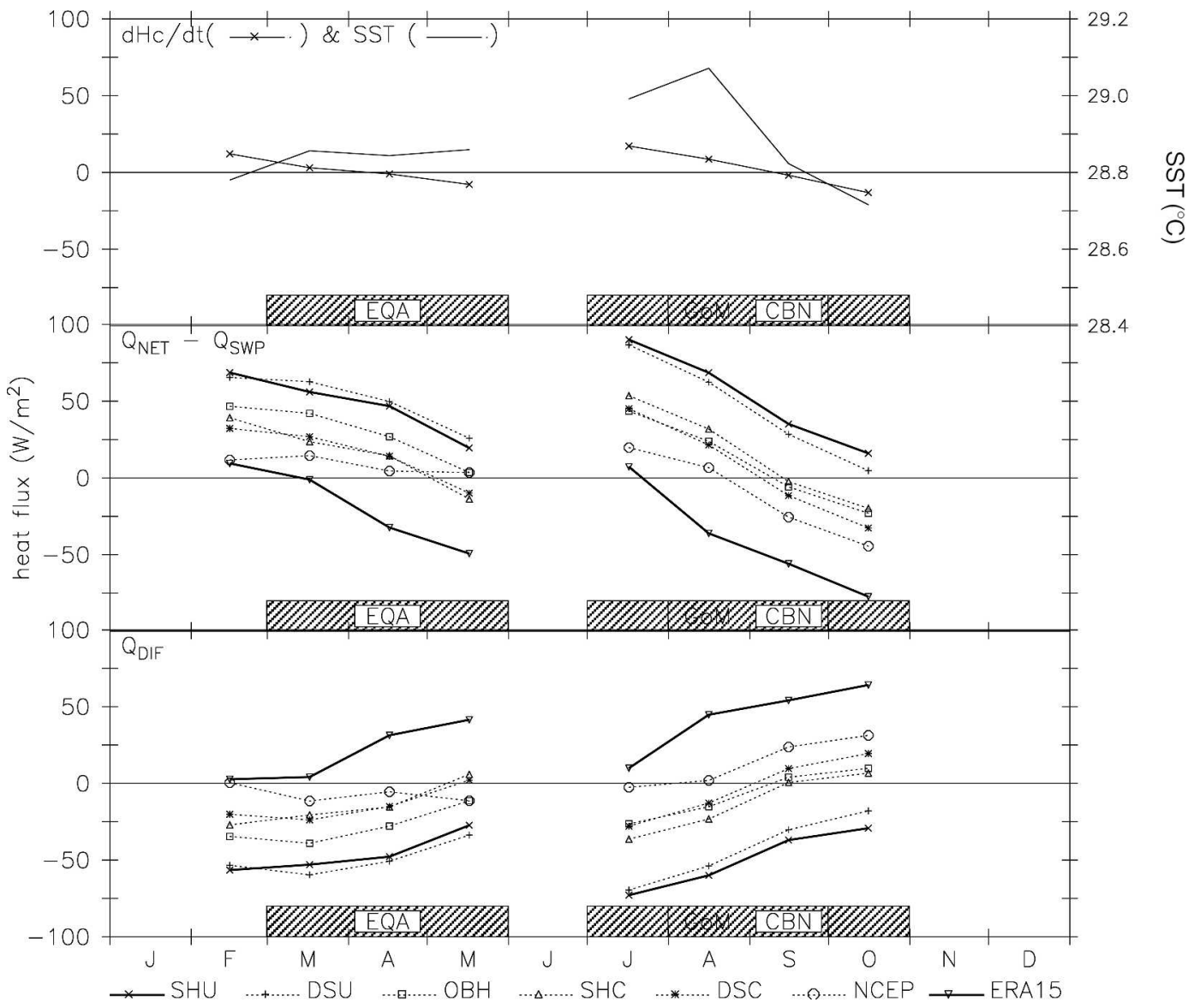

FIG. 9. For the Atlantic as in Fig. 8, but using the $28.5^{\circ} \mathrm{C}$ isotherm instead of $27.5^{\circ} \mathrm{C}$.

consistent with those of Toole et al. (2004) who used the SHU climatology. The OBH, SHC, and DSC surface fluxes yield results similar to those for the WHWP and also to the consensus range from IndoPacific observations. By this measure, previous studies of the Indo-Pacific warm pool combined with our own analysis indicate that the constrained (SHC, DSC) and Oberhuber surface fluxes are in the correct range for the Tropics and that the unconstrained datasets generally yield diffusion rates that are too high because they add too much heat to (or remove too little from) the ocean.

\section{c. In situ flux estimates}

We try to test our conclusions regarding surface fluxes by comparison with in situ-based surface flux estimates. For the Pilot Research Array in the Tropical Atlantic (PIRATA) (PIRATA; Servain et al. 1998) we average the 5-yr (1997-2001) flux estimates from Foltz et al. (2003) for the EQA (March-April-May) based on moorings at $10^{\circ}, 23^{\circ}$, and $35^{\circ} \mathrm{W}$ on the equator. We also average the estimates for the PIRATA moorings at $8^{\circ}$ and $12^{\circ} \mathrm{N}$ along $38^{\circ} \mathrm{W}$, which corresponds to the eastern extension of the western Atlantic warm pool (TNA) during August-September-October, but not to the core of the warm pool in the Caribbean. For the ENP region and season (AMJ) we have averaged identically estimated 4-yr (2000-03) fluxes from the Tropical Atmosphere Ocean/Eastern Pacific Investigation of Climate Processes (TAO/EPIC) moorings at $6^{\circ}, 8^{\circ}, 10^{\circ}$, and $12^{\circ} \mathrm{N}$ along $95^{\circ} \mathrm{W}$ (G. R. Foltz 2004, personal communication). There appear to be no research-quality airsea mooring data for CBN, while in GoM such data only exist over shelf regions, which we do not feel are representative of GoM as a whole. Table 6 gives the comparison between six of the surface flux climatologies and PIRATA for the ENP, TNA, and EQA regions during their respective seasons of maximum development. Component flux climatologies do not exist for the DSC data. Only the evaporative $\left(Q_{\mathrm{EVP}}\right)$ and shortwave $\left(Q_{\mathrm{SWR}}\right)$ fluxes are considered, which are the principal sources of discrepancy between net flux datasets. To assess the impact of the component flux 
TABLE 5. WHWP bubble analysis heat budget residuals $\left(Q_{\text {DIF }} ; \mathrm{W} \mathrm{m}^{-2}\right)$, shown for the (upper tier) WOD01 and (lower tier) GDEM hydrothermal climatologies and for all three defining isotherms. The results are grouped by the 3-month periods and basins within which each of the four subregions is at maximum development. Columns are ranked from left to right according to the average amount of heat absorbed by the ocean annually in the Western Hemisphere Tropics $\left(30^{\circ} \mathrm{S}-30^{\circ} \mathrm{N}\right.$, Africa to $\left.120^{\circ} \mathrm{W}\right)$.

\begin{tabular}{|c|c|c|c|c|c|c|c|c|}
\hline Region & $T_{0}$ & SHU & DSU & $\mathrm{OBH}$ & DSC & SHC & NCEP1 & ERA-15 \\
\hline \multirow[t]{3}{*}{ ENP (Apr-Jun) } & 28.5 & -48.7 & -48.0 & -18.7 & -9.6 & -15.1 & -17.1 & 6.1 \\
\hline & 28.0 & -54.4 & -52.1 & -23.9 & -13.8 & -20.3 & -25.3 & 4.1 \\
\hline & 27.5 & -54.5 & -51.6 & -23.3 & -13.5 & -20.2 & -27.3 & 2.5 \\
\hline \multirow[t]{3}{*}{ GOM (Jul-Sep) } & 28.5 & -56.6 & -51.2 & -12.5 & -10.4 & -19.7 & 7.7 & 36.2 \\
\hline & 28.0 & -53.2 & -50.4 & -8.1 & -9.8 & -16.2 & 15.1 & 38.5 \\
\hline & 27.5 & -50.6 & -50.6 & -7.6 & -10.4 & -13.4 & 13.9 & 38.6 \\
\hline \multirow[t]{3}{*}{ CBN (Aug-Oct) } & 28.5 & -42.0 & -34.0 & -0.5 & 5.4 & -5.3 & 19.0 & 54.3 \\
\hline & 28.0 & -45.6 & -41.5 & -6.1 & -2.4 & -8.8 & 15.9 & 51.0 \\
\hline & 27.5 & -46.9 & -45.0 & -8.5 & -6.1 & -9.7 & 11.4 & 49.4 \\
\hline \multirow{3}{*}{ EQA (Mar-May) } & 28.5 & -42.7 & -48.0 & -26.1 & -12.3 & -10.0 & -9.4 & 25.6 \\
\hline & 28.0 & -48.1 & -52.8 & -23.7 & -16.4 & -14.0 & -10.8 & 30.5 \\
\hline & 27.5 & -53.5 & -56.7 & -23.9 & -19.7 & -18.0 & -11.6 & 30.4 \\
\hline \multirow[t]{3}{*}{ ENP (Apr-Jun) } & 28.5 & -45.9 & -45.5 & -16.3 & -8.0 & -12.9 & -14.7 & 6.3 \\
\hline & 28.0 & -49.1 & -46.9 & -18.6 & -9.3 & -15.6 & -19.5 & 5.3 \\
\hline & 27.5 & -48.9 & -46.1 & -18.0 & -8.5 & -15.1 & -21.0 & 3.6 \\
\hline \multirow{3}{*}{ GOM (Jul-Sep) } & 28.5 & -56.2 & -50.5 & -14.2 & -11.9 & -21.4 & 2.9 & 29.6 \\
\hline & 28.0 & -53.4 & -50.4 & -9.1 & -11.6 & -17.9 & 13.2 & 29.9 \\
\hline & 27.5 & -53.8 & -53.2 & -11.0 & -14.5 & -17.9 & 8.6 & 29.5 \\
\hline \multirow[t]{3}{*}{ CBN (Aug-Oct) } & 28.5 & -41.3 & -32.0 & -0.9 & 5.4 & -6.8 & 13.8 & 49.5 \\
\hline & 28.0 & -46.8 & -41.4 & -6.5 & -3.6 & -11.1 & 15.5 & 44.7 \\
\hline & 27.5 & -48.9 & -46.0 & -10.2 & -8.5 & -13.1 & 8.7 & 42.0 \\
\hline \multirow[t]{3}{*}{ EQA (Mar-May) } & 28.5 & -49.2 & -53.6 & -30.7 & -18.9 & -17.4 & -12.9 & 18.4 \\
\hline & 28.0 & -49.1 & -54.2 & -25.3 & -18.9 & -15.8 & -12.5 & 26.6 \\
\hline & 27.5 & -53.0 & -56.4 & -23.9 & -20.4 & -18.7 & -12.7 & 25.7 \\
\hline
\end{tabular}

biases on the net surface heat flux, we add $Q_{\mathrm{EVP}}$ and $Q_{\text {swR }}$ for all data sources and subtract the mooring sum from those of the six climatologies.

The rms differences between the six climatologies and PIRATA are $20-28 \mathrm{~W} \mathrm{~m}^{-2}$ for both fluxes and all regions except for the TNA $\left(7 \mathrm{~W} \mathrm{~m}^{-2}\right.$ for latent heat flux). The discrepancies between the six climatologies for the summed fluxes (PIRATA subtracted) have rms values of $38-50 \mathrm{~W} \mathrm{~m}^{-2}$ for all possible pairings. In the Atlantic, shortwave radiation is closest to the PIRATA measurements for the SHC climatology in both regions, while the unconstrained climatologies (SHU, DSU) heat the ocean more and the model-based ones (NCEP1, ERA-15) heat the ocean less than PIRATA. This is qualitatively consistent with our conclusion about the net fluxes from the bubble analysis. However,

TABLE 6. (upper tier) Comparison between the TAO/EPIC in situ estimates of the evaporative (EVP) and shortwave (SWR) heat fluxes $\left(\mathrm{W} \mathrm{m}^{-2}\right)$ for the eastern North Pacific (ENP; $\left.6^{\circ}-12^{\circ} \mathrm{N}\right)$ and six climatologies used in this study, at collocated grid points. (middle tier) As in the upper tier but for the PIRATA moorings in the tropical North Atlantic (TNA; $8^{\circ}-12^{\circ} \mathrm{N}$ ). (lower tier) As in the upper tier but for the PIRATA moorings in the equatorial Atlantic $\left(\mathrm{EQA} ; 10^{\circ}-35^{\circ} \mathrm{W}\right)$. Each region is averaged for the respective season of maximum warm pool development (AMJ, ASO, MAM). In the third row of each tier the SWR and EVP values are added for all columns and the mooring sum is subtracted from the climatology sums. Signs are positive for ocean warming.

\begin{tabular}{|c|c|c|c|c|c|c|c|}
\hline & SHC & $\mathrm{OBH}$ & SHU & DSU & NCEP1 & ERA-15 & EPIC or PIRATA \\
\hline SWR (ENP-AMJ) & 214.7 & 187.0 & 228.3 & 236.5 & 204.1 & 170.7 & 202.6 \\
\hline EVP (ENP-AMJ) & -114.1 & -91.9 & -96.1 & -103.0 & -99.3 & -110.0 & -102.2 \\
\hline $\mathrm{SWR}+\mathrm{EVP}-\mathrm{EPIC}$ & 0.2 & -5.3 & 31.8 & 33.1 & 4.4 & -39.7 & \\
\hline SWR (TNA-ASO) & 205.6 & 188.3 & 218.6 & 229.7 & 209.6 & 171.3 & 207.1 \\
\hline EVP (TNA-ASO) & -119.2 & -100.3 & -100.4 & -105.5 & -115.3 & -147.0 & -102.4 \\
\hline SWR + EVP - PIRATA & -18.3 & -16.7 & 13.5 & 19.5 & -10.4 & -80.4 & \\
\hline SWR (EQA-MAM) & 217.0 & 188.8 & 230.7 & 231.0 & 198.9 & 186.2 & 219.7 \\
\hline EVP (EQA-MAM) & -99.5 & -81.7 & -83.8 & -86.9 & -83.8 & -116.2 & -67.0 \\
\hline SWR + EVP - PIRATA & -35.2 & -45.6 & -5.8 & -8.6 & -37.6 & -82.7 & \\
\hline
\end{tabular}


for the evaporative heat flux the unconstrained climatologies lie closest to the PIRATA values in the TNA region, while all climatologies remove significantly more heat from the EQA region than PIRATA. When evaporation and shortwave are summed together, the biases with respect to PIRATA in the TNA region are such that $\mathrm{SHC}$ and $\mathrm{OBH}$ show an excess heat removal $\left(\sim 17\right.$ to $18 \mathrm{~W} \mathrm{~m}^{-2}$ ) while SHU and DSU show an equally excessive heat gain by the ocean.

In the ENP region $\mathrm{SHC}, \mathrm{OBH}$, and $\mathrm{NCEP} 1$ have the smallest overall biases (differences), but the NCEP1 bias is based on components with small biases whereas $\mathrm{SHC}$ and $\mathrm{OBH}$ are based on components with larger but offsetting biases. SHU and DSU put too much heat into the ocean vis-à-vis the moorings mainly due to greater shortwave radiation, while ERA-15 removes too much heat with both components.

Implicit assumptions in these comparisons are that the mooring estimates are the most accurate and that the several-year averaging periods for the moorings are not anomalous with respect to the much larger averaging periods for the flux climatologies. Under these assumptions, no one climatology consistently underperforms the others in all regions, with the exception of ERA-15, which invariably removes more heat from (adds less to) the ocean than the other five. As suggested by the bubble analysis, SHU and DSU add more heat to the ocean in the TNA and ENP regions. But in the EQA (where we are least confident of the bubble approach), the unconstrained climatologies are the most accurate and others remove too much heat. SHU and DSU consistently heat the ocean more with shortwave radiation and $\mathrm{OBH}$ consistently less. All climatologies give too much evaporative cooling in the equatorial Atlantic. No single dataset is best in all regions.

\section{d. Surface forcing of the warm pool}

In the bubble analysis the advective flux divergence disappears and the residual estimate of diffusion does not suggest any temporal variability that can relate to the onset and demise of the warm pool. Hence, while $Q_{\text {DIF }}$ is needed to close the overall budget, the annual cycle of warm pool development must be related to the components of the net surface heat flux. Therefore, we wish to look at the component surface fluxes and their relation to the warm pool cycle. The relevant terms are shown in Figs. 10 and 11 for the ENP and Atlantic warm pools, respectively, using only the $27.5^{\circ} \mathrm{C}$ bounding isotherm to compute the area-averaged SST, heat storage rate, and fluxes. We do not include the net longwave flux nor the sensible heat flux, both of which have only small seasonal variations with no apparent relevance to warm pool development. Since it is only the seasonal variations we are interested in, we have removed the annual mean fluxes. To minimize the biasing effects of surface flux parameterization errors on the calculations, we use only $Q_{\mathrm{NET}}$ for the SHC dataset, one of the three selected in section $4 \mathrm{~b}$. The conclusions are unaffected by using either DSC or OBH.

For the ENP (Fig. 10), the sharp SST maximum in April-June is preceded by February-April maxima in $Q_{\text {NET }}$ and storage rate, and followed by minima in May-July. Also, we see that $Q_{\text {NET }}$ is mimicked most closely by the solar radiation $\left(Q_{\mathrm{SWR}}\right)$ in both phase and amplitude, and by latent heat in phase but with a smaller amplitude (middle panel). The onset of the large shortwave flux $\left(Q_{\mathrm{SWR}}\right)$ in late winter is clearly controlled by a sharp increase in solar radiation at the top of the atmosphere $\left(Q_{\mathrm{TOA}}\right)$ related to the solar declination (bottom panel). However, the subsequent decrease in April-May is mainly caused by a concurrent increase in cloud cover as the North American monsoon season begins. Evaporative heat loss $Q_{\mathrm{EVP}}$ is minimum in winter (largest values of the seasonal anomaly) when the warm pool is coolest, and it becomes maximum (negative values) in May-July after the warmest SSTs are established. Examination of the wind speeds (not shown) does not suggest that evaporation responds to winds in the context of the annual cycle, rather, to the SST. The penetrative shortwave flux $\left(Q_{\text {SwP }}\right)$ appears to be passive, presenting maximum loss in winter when the warm pool is small and shallow, and minimum loss in April-June when the warm pool is largest and deepest. Less shortwave radiation penetrates the $27.5^{\circ} \mathrm{C}$ bubble as the warm pool grows and deepens, thus helping to persist the warm pool maximum. Hence, it seems clear that the warm pool first develops in response to increasing solar radiation as the solar declination approaches zero in late winter. Then, as SST and the warm pool size approach their spring maximum, evaporation and convection increase, associated with the onset of the Mexican monsoon, and cloudiness also increases, so that both $Q_{\mathrm{SWR}}$ and $Q_{\mathrm{EVP}}$ contribute to the cooling and contraction of the warm pool following the late spring maximum.

The relationships in the Atlantic (Fig. 11) are complicated by a strong double maximum in the warm pool, one in March-May associated with the equatorial Atlantic, the other in late summer centered over the Caribbean. As in the ENP, the SST maxima are preceded by respective maxima in $Q_{\mathrm{NET}}, d H / d t$, and $Q_{\mathrm{SWR}}$, and the incident shortwave radiation is controlled by the solar declination $\left(Q_{\mathrm{TOA}}\right)$. There are also increases in evaporative heat loss following the subregional warm pool maxima, but they are not as large as in the Pacific. 


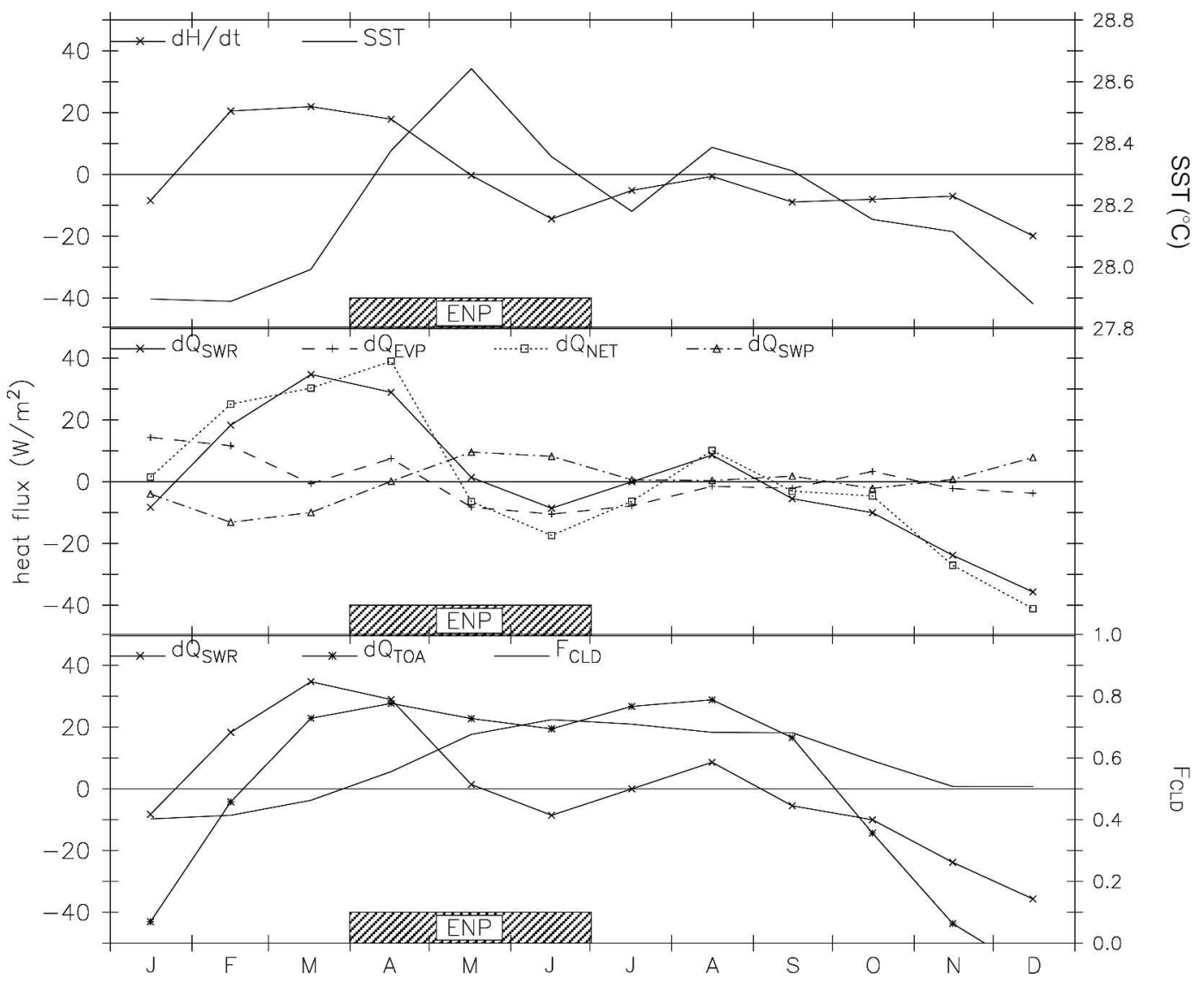

FIG. 10. Annual variation of surface forcing terms for the constant isotherm region (bubble) in the eastern North Pacific, using the $27.5^{\circ} \mathrm{C}$ isotherm. (top) Sea surface temperature $\left({ }^{\circ} \mathrm{C}\right.$, solid) and heat storage rate ( $\mathrm{W} \mathrm{m}^{-2}$, solid + symbol) from the Levitus hydrothermal climatology; (middle) heat flux terms with large seasonal cycles from the constrained Southampton surface heat flux climatology (SHC), namely, shortwave radiative flux $\left(Q_{\mathrm{Sw}}\right)$, latent heat flux $\left(Q_{\mathrm{EVP}}\right)$, penetrative shortwave flux $\left(Q_{\mathrm{SWP}}\right)$, and also the net surface heating $\left(\mathrm{Q}_{\mathrm{NET}}\right)$, all with their annual means removed; and (bottom) the net shortwave radiative flux at the sea surface $\left(Q_{\text {SwR }}\right)$, downward shortwave radiative flux at the top of the atmosphere $\left(Q_{\mathrm{TOA}}\right)$, with their annual means removed in both, and the cloud fraction.

More than in the Pacific, the annual cycle of the Atlantic warm pool is dominated by solar declination in all phases of its evolution.

\section{Slab-layer analysis}

In this section we consider the heat balance of a slab volume of constant thickness within each of several subregions of the warm pool: ENP, GoM, CBN, and EQA (Fig. 1). For each subregional slab, the horizontal boundaries are defined by land (the coastal boundaries of the WOD01 grid) or by the approximate extent of the $28^{\circ} \mathrm{C}$ isotherm boundary during the season of maximum warm pool development in the subregion. The slab thickness is taken to be $30 \mathrm{~m}$ for convenience in using surface drifter data (15-m drogue depth) as an independent estimate of horizontal advection (next sec- tion). Thirty meters is not far from the warm pool depth as defined by the $27.5^{\circ} \mathrm{C}$ isotherm, and the bubble analysis shows that the residual estimates of diffusive flux are not sensitive to the volume depth (Table 5).

In combination with the bubble analysis just described, the slab-layer procedure offers further advantages for understanding the heat balance. For a slab, the heat balance Eq. (1) now contains an additional term $\oiint_{A_{T}} Q_{\mathrm{ADV}} d s$ for the combined vertical and horizontal heat advection through the bottom and side boundaries, respectively. Terms A, B, and C are calculated as before for the slab surface areas, but from the bubble analysis we can now exclude all of the surface flux climatologies except for DSC, SHC, and OBH. For term D we use the residual estimates of $Q_{\text {DIF }}$ from the $27.5^{\circ} \mathrm{C}$ bubble analysis corresponding to each of the retained surface flux estimates. Besides having a warm 


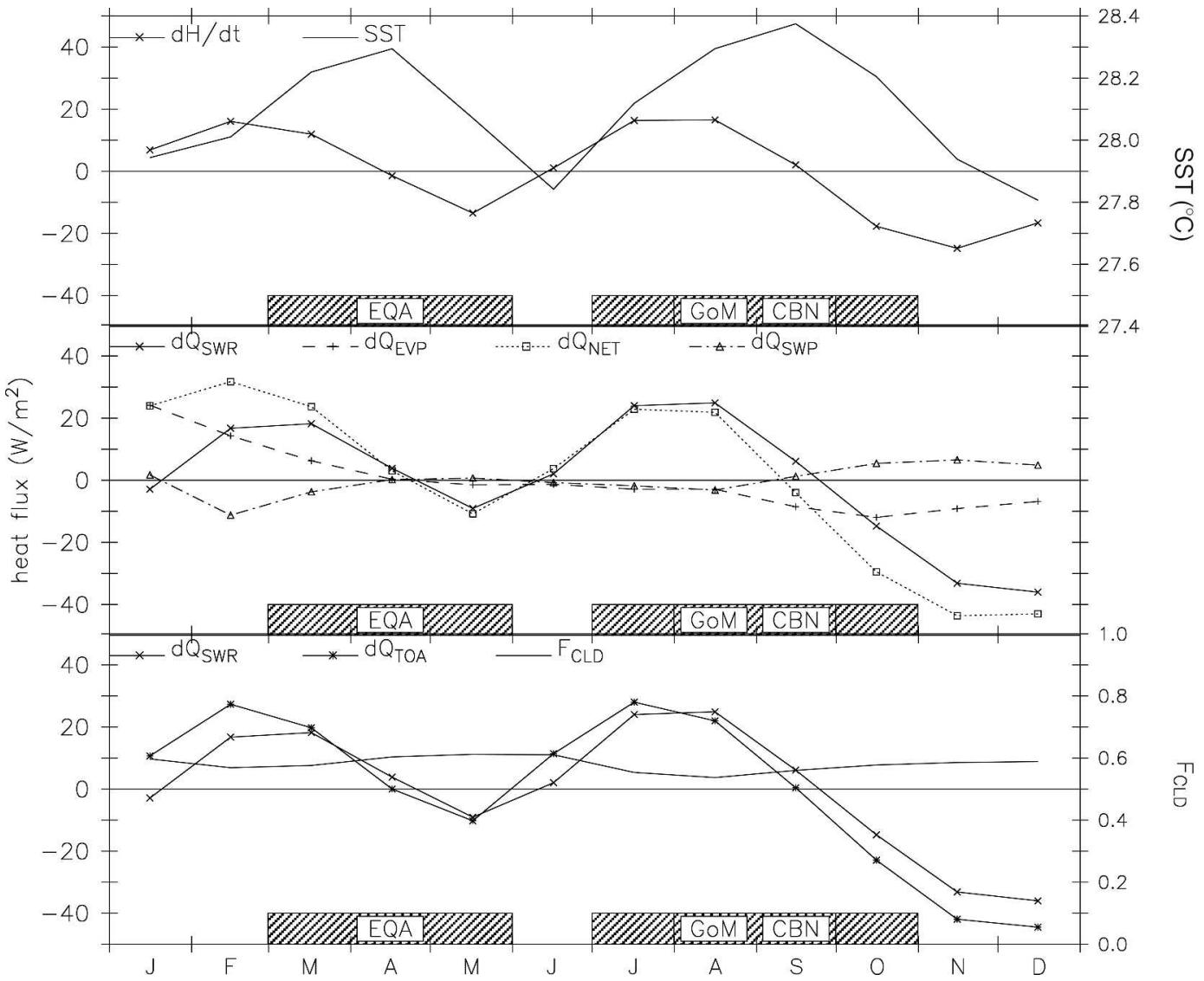

FIG. 11. As in Fig. 10, but for the Atlantic portion of the WHWP.

pool depth closest to $30 \mathrm{~m}, 27.5^{\circ} \mathrm{C}$ comes closest to including the entire slab region during the respective seasons of maximum warm pool development. We use the average seasonal value of $Q_{\mathrm{DIF}}$ appropriate for the season of maximum warm pool development within each subregion (Table 5). The residual from the slab analysis $Q_{\text {RES }}$ represents the total advective contribu- tion to the balance $Q_{\mathrm{ADV}}$. However, because the residual also contains the sum of all errors in the storage and surface flux terms, one cannot accept them at face value as estimating the advective heat flux divergence. Hence, in the next section we will make direct estimates of the advective contribution for comparison.

The results are summarized in Table 7 . Here we do

TABLE 7. Rows summarize the slab heat balance for the four subregions and their respective seasons of maximum development, using the bubble residuals for the $28.0^{\circ}$ and $27.5^{\circ} \mathrm{C}$ isotherms (Table 5) as estimates for the total diffusive heat flux [Eq. (2), term D]. Columns from left to right are the bounding temperature $\left({ }^{\circ} \mathrm{C}\right)$, the WOD01 storage rate, the net heating and diffusion from the three optimal surface flux climatologies, and the corresponding residuals taken as estimates of the total advective heat flux divergence. (Units: $\mathrm{W} \mathrm{m}^{-2}$.)

\begin{tabular}{|c|c|c|c|c|c|c|c|c|c|c|c|}
\hline \multirow[b]{2}{*}{ Area } & \multirow[b]{2}{*}{$T_{0}$} & \multirow{2}{*}{$\begin{array}{c}d H / d t \\
\text { WOD01 }\end{array}$} & \multicolumn{3}{|c|}{$Q_{N E T}-Q_{S W P}$} & \multicolumn{3}{|c|}{$Q_{D I F}$} & \multicolumn{3}{|c|}{$Q_{R E S}$} \\
\hline & & & $\mathrm{OBH}$ & DSC & SHC & $\mathrm{OBH}$ & DSC & SHC & $\mathrm{OBH}$ & DSC & SHC \\
\hline \multirow{2}{*}{ ENP (Apr-Jun) } & 28.0 & -0.4 & 24.6 & 13.5 & 19.0 & -23.9 & -13.8 & -20.3 & -1.1 & -0.1 & 0.9 \\
\hline & 27.5 & 0.0 & 28.3 & 18.0 & 23.1 & -23.3 & -13.4 & -20.2 & -5.0 & -4.6 & -2.9 \\
\hline \multirow{2}{*}{ GoM (Jul-Sep) } & 28.0 & 2.2 & 24.9 & 19.3 & 29.0 & -8.1 & -9.8 & -16.2 & -14.6 & -7.3 & -10.6 \\
\hline & 27.5 & 4.7 & 27.9 & 23.1 & 32.5 & -7.6 & -10.4 & -13.4 & -15.6 & -8 & -14.4 \\
\hline \multirow[t]{2}{*}{ CBN (Aug-Oct) } & 28.0 & 8.1 & 14.6 & 20.4 & 25.2 & -6.1 & -2.4 & -8.8 & -0.4 & -9.9 & -8.3 \\
\hline & 27.5 & 10.7 & 17.4 & 24.0 & 28.5 & -8.5 & -6.1 & -9.7 & 1.8 & -7.2 & -8.1 \\
\hline \multirow[t]{2}{*}{ EQA (Mar-May) } & 28.0 & -5.5 & 26.5 & 21.5 & 21.0 & -23.7 & -16.4 & -14.0 & -8.3 & -10.6 & -12.5 \\
\hline & 27.5 & -6.9 & 33.3 & 29.8 & 28.8 & -23.9 & -19.7 & -18.0 & -16.3 & -17.0 & -17.7 \\
\hline
\end{tabular}


not include estimates for the $28.5^{\circ} \mathrm{C}$ isotherm because the depth of $28.5^{\circ} \mathrm{C}$ is the least appropriate for the $30-\mathrm{m}$ slabs (Table 2) and the portion of the ENP slab covered by water warmer than $28.5^{\circ} \mathrm{C}$ is too small. The corresponding values of $Q_{\mathrm{DIF}}$ (term $\mathrm{D}$ in the slab balance) are repeated from Table 5. Because in the bubble analysis the magnitude of $Q_{\mathrm{DIF}}$ varies in proportion to the heat absorbed but with opposite sign, differences in terms B and C (between the three surface flux datasets) are largely offset by corresponding differences in the bubble estimate for $Q_{\mathrm{DIF}}$ (term D). This causes the residual estimates of $Q_{\mathrm{ADV}}$ for the slabs to be stable and collapse on a relatively narrow range of values. The slab balances yield less than $-10 \mathrm{~W} \mathrm{~m}^{-2}$ of estimated total advective cooling for the ENP and $\mathrm{CBN}$, and somewhat more cooling for GoM and EQA.

\section{Advective heat flux divergence}

One would like to independently estimate the advective contributions so as to determine whether the balance so far constructed from the combined bubble and slab analyses is reasonable. Of the four subregions considered, the ones that offer the best prospects for such estimates are the ENP and GoM. The former has a relatively large amount of drifter data (with 15-m drogues) that have accumulated over a 20 -yr period; the latter because, although the drifters are much less plentiful, they are constrained to enter through the narrow Yucatan Channel and exit through the Florida Straits (between Key West and Cuba). Too little is known about the transports through the Antillean passages to attempt an estimate for the Caribbean, and much less data are available to construct estimates for the open EQA region.

\section{a. Gulf of Mexico}

The annual mean 15-m drifter flows through the Yucatan Channel and Florida Straits are shown in Fig. 12 (Lumpkin 2003). More than $90 \%$ of the drifter data are for 1999-2003 and provide about 300 drifter days of information for the constricted domain of each channel. This is about equal to the drifter coverage spread over the much larger domain of the subtropical North Atlantic but considerably less than that afforded by $20 \mathrm{yr}$ of drifter data in the ENP region. The cross-channel distribution of flow through the Yucatan Channel looks remarkably similar to that shown by the best measurements to date from a 2-yr cross-channel array of current meters and acoustic Doppler profilers (Sheinbaum et al. 2002, their Fig. 2a). The annual average $0-30-\mathrm{m}$ through-channel transport is $M_{Y}=3.1 \mathrm{~Sv}$

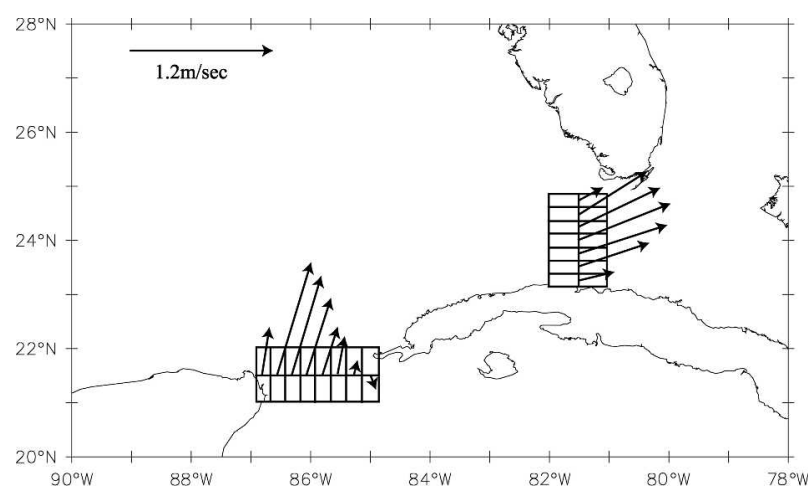

FIG. 12. Vector estimates of annual average horizontal flow $\left(\mathrm{m} \mathrm{s}^{-1}\right)$ from surface drifters with $15-\mathrm{m}$ drogues. Data have been binned into the boxes shown with $1 / 4^{\circ}$ latitude cross-channel width and $6^{\circ}$ latitude length in the through-channel direction. For the bin closest to Yucatan (no data) the flow is interpolated between the coast (zero) and the next bin to the east.

( $1 \mathrm{~Sv} \equiv 10^{6} \mathrm{~m}^{3} \mathrm{~s}^{-1}$ ) and $M_{F}=3.6 \mathrm{~Sv}$ for the Yucatan and Florida Straits, respectively, and the corresponding annual average cross-channel SSTs (Reynolds and Smith 1994) are $T_{Y}=27.6^{\circ} \mathrm{C}$ and $T_{F}=26.8^{\circ} \mathrm{C}$. During the warm pool season (July-September) the down-gulf SST gradient becomes slightly reversed $\left(0.3^{\circ} \mathrm{C}\right.$ warmer at the Florida Straits). To estimate the horizontal heat advection through the channels we bin the perpendicular component of the 15 -m drifter velocities into quarter-degree cross-channel boxes as shown in Fig. 12 and assume that they are the averages for the 0-30-m layer. These are multiplied by the Reynolds and Smith (1994) SST interpolated to the bins, and the product is integrated across the channel.

We estimate the vertical component of transport through the base of the slab from two climatologies of wind stress curl (da Silva and Southampton) interpolated to the WOD01 hydrothermal grid,

$$
M_{30}=f^{-1} \oiint_{A} \nabla \times \tau d s .
$$

The vertical advective heat flux across the base of the slab is estimated from the area integral of the product of $1^{\circ}$ gridded wind stress curl $\left(M_{30}\right)$ and WOD01 temperatures $\left(T_{30}\right)$.

There is good agreement between the wind stress climatologies. Anticyclonic winds dominate the Gulf from late winter through summer and fall, yielding up to $1 \mathrm{~Sv}$ of downwelling (in July), while weak upwelling prevails from October through January for an annual average downwelling of $-0.4 \sim-0.5 \mathrm{~Sv}$. This implies that the average annual Yucatan transport must exceed the Florida transport by a similar amount, which is opposite to the drifter result. However, although the 
TABLE 8. Rows summarize the overall heat balance for the four subregions and their respective seasons of maximum development, using only the three optimal surface flux climatologies (DSC, SHC, OBH) and the corresponding diffusion estimates averaged for the $28.0^{\circ}$ and $27.5^{\circ} \mathrm{C}$ isotherms. Columns from left to right are the WOD01 storage rate; the net heating from Table 7; the bubble residual estimate of $Q_{\mathrm{DIF}}$ from Table 4; and the slab residual estimate of the total advective heat flux divergence. Each of the flux columns is a range separated by dotted vertical lines based on the surface fluxes. The column on the far right gives the range of total advective heat flux divergence directly estimated from drifter observations and the da Silva and Southampton wind stress climatologies. (Units: $\mathrm{W} \mathrm{m} \mathrm{m}^{-2}$.)

\begin{tabular}{|c|c|c|c|c|c|c|c|c|c|}
\hline \multirow{2}{*}{$\frac{\text { Region }}{\text { ENP (Apr-Jun) }}$} & \multirow{2}{*}{$\begin{array}{c}\begin{array}{c}d H / d t \\
\text { (WOD01) }\end{array} \\
-0.2\end{array}$} & \multicolumn{2}{|c|}{$Q_{\mathrm{NET}}-Q_{\mathrm{SWP}}$} & \multicolumn{2}{|c|}{$Q_{\mathrm{DIF}}$} & \multicolumn{2}{|c|}{$Q_{\mathrm{RES}}$} & \multicolumn{2}{|c|}{$Q_{\mathrm{ADV}}$} \\
\hline & & 26.5 & 15.8 & -23.6 & -13.6 & -3.3 & -1.3 & -2.0 & -2.0 \\
\hline GoM (Jul-Sep) & 3.5 & 30.8 & 21.2 & -14.7 & -7.9 & -15.1 & -7.6 & -5.5 & -5.4 \\
\hline CBN (Aug-Oct) & 9.4 & 26.9 & 16.0 & -9.3 & -4.3 & -8.5 & 0.7 & - & - \\
\hline EQA (Mar-May) & -6.2 & 29.9 & 24.9 & -23.8 & -16.0 & -15.1 & -12.3 & - & - \\
\hline
\end{tabular}

drifter estimates may contain appreciable errors, the wind stress curl does not resolve vertical velocities in the narrow coastal zones surrounding the WOD01 $1^{\circ} \times$ $1^{\circ}$ grid. Upwelling is known to occur seasonally around the Gulf, over the shallow Campeche banks, the northeastern Gulf coast, and the west Florida shelf. Compensating coastal downwellings probably also occur (Virmani and Weisberg 2003). It is thus impossible to accurately close the mass balance or to know which of the competing mass fluxes is more correct.

The mass imbalance $M_{\Delta}$ remaining from the independent estimates of horizontal and vertical mass transport is comprised of measurement error and unresolved mass transports. This imbalance is applied as a correction term $Q_{\Delta}=\rho c_{p} M_{\Delta} T_{\Delta} / A$, where $A$ is the slab area and $T_{\Delta}$ is the average temperature of the slab volume (since we do not know how $M_{\Delta}$ is distributed over the surfaces of the slab). The horizontal, vertical, and correction fluxes are summed to estimate the total advective heat flux divergence. Total advection accounts for about $+8 \mathrm{~W} \mathrm{~m}^{-2}$ of warming during the winter months largely due to the downstream temperature decrease and the predominant downwelling. During the warm pool season (July-September) there is a net cooling of about $-5 \mathrm{~W} \mathrm{~m}^{-2}$ due to the reversal of the down-gulf SST gradient.

Although the errors in the measured transports are not small, the estimate of total heat flux divergence is stable within a narrow uncertainty range due to the application of the continuity correction term. Large changes in the measured transports are taken up by the correction term and applied at a temperature that is only a few tenths of a degree different. For example, if the value of $T_{\Delta}$ is taken to be $T_{30}$ or the SST (the possible extremes), our estimate changes by only 2 to 3 $\mathrm{W} \mathrm{m} \mathrm{m}^{-2}$ one way or the other. In other words, if the true value of either component transport were known to differ by $M_{\Delta}$ from our estimates, the resulting total advective heat flux divergence would be essentially un- changed. The uncertainty of the individual horizontal and vertical component heat flux divergences is much larger due to the lack of a transport constraint.

\section{b. Eastern North Pacific}

For the ENP, the total advective heat flux divergence of the slab layer is estimated in similar fashion. The horizontal component is estimated from the product of temperature and the perpendicular drifter flow, both averaged for $1^{\circ}$ squares around the slab perimeter. As for the GoM slab, the vertical transport through $Z=30$ $\mathrm{m}$ is estimated from the area-integrated product of wind stress curl and slab-base temperature, and a correction term is applied using the error transport computed from the mass imbalance between the independently estimated vertical and horizontal transports, together with an average temperature for the volume. From this we find that the ENP region is cooled by total advection throughout the year, ranging from $\sim-10$ to $-15 \mathrm{~W} \mathrm{~m}^{-2}$ in winter to near zero in summer and about $-2 \mathrm{~W} \mathrm{~m}^{-2}$ during the warm pool season (April-June).

\section{Discussion}

The overall balance is shown in Table 8 for the four subregions (Fig. 1) with ranges combined and summarized for the $28.0^{\circ}$ and $27.5^{\circ} \mathrm{C}$ isotherms and based on the three most acceptable surface flux climatologies (OBH, SHC, DSC). The three surface flux climatologies yield a surface ocean warming of +20 to $+30 \mathrm{~W}$ $\mathrm{m}^{-2}$ that is partially offset by -5 to $-25 \mathrm{~W} \mathrm{~m}^{-2}$ of cooling through combined horizontal and vertical turbulent diffusion. The balance is closed by an estimated cooling ( 0 to $-10 \mathrm{~W} \mathrm{~m}^{-2}$ ) by the total advective heat flux divergence $Q_{\mathrm{RES}}$ (slab residual) in the ENP and CBN, and -5 to $-15 \mathrm{~W} \mathrm{~m}^{-2}$ for the GoM and EQA. For the GoM and ENP subregions there is remarkably good agreement from direct observations (wind stress and 
drifters) for the total heat advection $Q_{\mathrm{ADV}}$, as compared with the slab-layer residuals, $Q_{\mathrm{RES}}$. This gives us confidence in our results for those regions and for the others as well and confirms our selection of surface flux datasets.

We cannot say very much about the horizontal versus vertical components of $Q_{\mathrm{DIF}}$ and $Q_{\mathrm{ADV}}$. It seems unlikely that horizontal diffusion is important in the Gulf of Mexico or Caribbean. In the Gulf of Mexico the only open boundaries have strong steady flows. Although North Brazil Current eddies impinge on the Caribbean from the east, the zonal temperature gradients between the Caribbean and the open Atlantic are generally small. Hence the total diffusion estimates in Table 8 are likely to be primarily vertical. Horizontal diffusion may be more important in the ENP and EQA regions, in the former due to the presence of the Tehuantepec and Papagayo eddies in the late winter and early spring and in both regions due to tropical instability waves near the equator.

Inclusion of the mass imbalance correction yields narrow and stable estimates of the total observed advective heat flux divergence $Q_{\mathrm{ADV}}$ that agree with the slab-layer residuals (Table 8). However, efforts to estimate the horizontal and vertical components of $Q_{\mathrm{ADV}}$, through assumptions of how the mass imbalance correction is partitioned between the bottom and sides of the slabs, result in unstable results and large ranges that preclude any useful conclusions. We cannot discard the possibility that the two components have considerably larger but opposing values.

\section{Summary and conclusions}

We have used two hydrothermal datasets to define warm pool volumes and their heat storage rates for three defining isotherms and have constructed warm pool heat budgets using seven of the most commonly used surface heat flux climatologies. The problem of estimating the radiative heat loss through the bottom of shallow warm pools is addressed by using a spatially and temporally varying irradiance attenuation inferred from satellite color imagery, according to an algorithm (McLain et al. 2002) that is most consistent with historical direct measurements (e.g., Jerlov 1976).

The WHWP is comprised of four geographically separate subregions with distinct or overlapping seasons of maximum development. The eastern North Pacific (ENP) and equatorial Atlantic (EQA) are best developed in the boreal spring, while the Gulf of Mexico (GoM) and Caribbean (CBN) dominate during the early and late summer, respectively. Warm pool depths are similar to the mixed-layer depth (20-40 m) and are much less than for the Indo-Pacific warm pool (50-60 m).

Using a time-dependent variation of the Niiler and Stevenson (1982) heat balance for a constant warm pool bounding temperature we successfully narrow the number of surface flux climatologies that are acceptable for the Western Hemisphere Tropics from seven to three. The two climatologies based on the NCEP1 and ERA-15 reanalyses put too little heat into the warm pools, but especially in the Intra-Americas Sea, resulting in nonphysical (positive) residual estimates of the diffusive heat flux divergence. Comparison to mooring estimates suggests that NCEP1 may be acceptable in the ENP and eastern Atlantic (TNA) regions, but ERA-15 is unacceptable everywhere. Of the remaining five climatologies, the unconstrained fluxes (SHU, DSU) err on the opposite side, putting too much heat into the ocean and yielding diffusive cooling rates that are inconsistent (too large) with observational evidence for the Indo-Pacific warm pool. Mooring comparisons, however, suggest that SHU and DSU may be best in the EQA region. We conclude that away from the equator heat balance studies of warm tropical ocean regions give the best overall closure when using the globally constrained surface flux data of da Silva and Southampton. We cannot extend these conclusions to other regions of the globe such as the cold Tropics (e.g., southeast Pacific) or the extratropics. In general, no climatology of net heat flux seems to be consistently preferable in all regions, and discrepancies upward of $50 \mathrm{~W} \mathrm{~m}^{-2}$ between climatologies are common.

The remaining surface flux datasets of da Silva and Southampton (DSC, SHC, constrained) and Oberhuber $(\mathrm{OBH})$ have a much narrower range of surface warming $\left(+25 \pm 5 \mathrm{~W} \mathrm{~m}^{-2}\right)$ over the subregional slab layers, with associated bubble residual estimates of total diffusion of -5 to $-20 \mathrm{~W} \mathrm{~m}^{-2}\left( \pm 5 \mathrm{~W} \mathrm{~m}^{-2}\right)$ depending on the subregion considered. When these are then input into a slab-layer balance, we obtain relatively narrow estimates of cooling by total advective heat flux divergence of -2 to $-14 \mathrm{~W} \mathrm{~m}^{-2}\left( \pm 5 \mathrm{~W} \mathrm{~m}^{-2}\right)$. The latter are confirmed by more direct estimates using wind stress data and drifters for the GoM and ENP regions.

We conclude that the bubble (constant bounding temperature) and slab-layer (constant volume) approaches to the heat balance, when combined, are very effective at reducing the large uncertainty presented by the many surface flux climatologies presently available. By disqualifying the unacceptable surface flux datasets, these methods allow us to infer relatively stable and narrow ranges for the total diffusive and advective heat flux divergences.

Using the inferential (bubble and slab) methods it is 
not possible to separate the ocean heat flux estimates into their vertical and horizontal components. Doing so for vertical and horizontal advection will require direct measurements adequate to reduce the uncertainty presented by mass imbalances. Doing so for the diffusive (vertical) fluxes may require appropriate microstructure measurements at key sites within the warm pool regions so as to determine the vertical diffusivities.

Acknowledgments. Our thanks to Drs. Rick Lumpkin and Ajoy Kumar for processing the drifter and SeaWiFS data, to Dr. Greg Foltz for providing surface flux estimates from the TAO/EPIC moorings, and to Drs. Rick Lumpkin and Claudia Schmid for their presubmission reviews of the manuscript. This research was supported by the NOAA PACS/GAPP Program through awards under Cooperative Agreement NA67RJO149 to the Cooperative Institute for Marine and Atmospheric Studies.

\section{REFERENCES}

Bosilovich, M. G., 2002: On the vertical distribution of local and remote sources of water for precipitation. Meteor. Atmos. Phys., 80, 31-41.

Conkright, M. E., and Coauthors, 2002: World Ocean Atlas 2001: Objective Analyses, Data Statistics, and Figures. National Oceanographic Data Center CD-ROM dataset documentation, Silver Spring, MD, $17 \mathrm{pp}$.

da Silva, A. M., C. C. Young, and S. Levitus, 1994: Algorithms and Procedures. Vol. 1, Atlas of Surface Marine Data 1994, NOAA Atlas NESDIS 6, 83 pp.

Enfield, D. B., and D. A. Mayer, 1997: Tropical Atlantic sea surface temperature variability and its relation to El NiñoSouthern Oscillation. J. Geophys. Res., 102, 929-945.

Fairall, C. W., E. F. Bradley, D. P. Rogers, J. B. Edson, and G. S. Young, 1996: Bulk parameterization of air-sea fluxes for TOGA-COARE. J. Geophys. Res., 101, 3747-3764.

Foltz, G. R., S. A. Grodsky, and J. A. Carton, 2003: Seasonal mixed layer heat budget of the tropical Atlantic Ocean. $J$. Geophys. Res., 108, 3146, doi:10.1029/2002JC001584.

Gibson, J. K., P. Kållberg, S. Uppala, A. Hernandez, A. Nomura, and E. Serrano, 1997: ERA description. Re-Analysis (ERA) Project Report Series 1, 72 pp.

Grist, J. P., and S. A. Josey, 2003: Inverse analysis adjustment of the SOC air-sea flux climatology using ocean heat transport constraints. J. Climate, 16, 3274-3295.

Jerlov, N. G., 1976: Marine Optics. Elsevier, 226 pp.

Josey, S. A., E. C. Kent, and P. K. Taylor, 1998: The Southampton Oceanography Centre (SOC) Ocean-Atmosphere Heat, Momentum and Freshwater Flux Atlas. Southampton Oceanography Centre Rep. 6, 30 pp.

Kalnay, E., and Coauthors, 1996: The NCEP/NCAR 40-Year Reanalysis Project. Bull. Amer. Meteor. Soc., 77, 437-471.

Lumpkin, R., 2003: Decomposition of surface drifter observations in the Atlantic Ocean. Geophys. Res. Lett., 30, 1753 , doi:10.1029/2003GL017519.

McCreary, J. P., H. S. Lee, and D. B. Enfield, 1989: The response of the coastal ocean to strong offshore winds: With application to circulations in the Gulfs of Tehuantepec and Papagayo. J. Mar. Res., 47, 81-109.

McLain, C. R., J. R. Christian, S. R. Signorini, M. R. Lewis, I. Asanuma, D. Turk, and C. Dupouy-Douchement, 2002: Satellite ocean-color observations of the tropical Pacific Ocean. Deep-Sea Res., 49B, 2533-2560.

Morel, A., 1988: Optical modeling of the upper ocean in relation to its biogenous matter content (case I waters). J. Geophys. Res., 93 (C9), 10 749-10 768.

Niiler, P. P., and J. Stevenson, 1982: On the heat budget of tropical warm water pools. J. Mar. Res., 40 (Suppl.), 465-480.

Oberhuber, J. M., 1988: An atlas based on the "COADS" data set: The budget of heat, buoyancy and turbulent kinetic energy at the surface of the global ocean. Max-Planck-Institut für Meteorologie Rep. 15, 199 pp.

Ohlmann, J. C., 2003: Ocean radiant heating in climate models. $J$. Climate, 16, 1337-1351.

Ramanathan, V., B. Subasilar, G. J. Zhang, W. Conant, R. D. Cess, J. T. Kiehl, H. Grassl, and L. Shi, 1995: Warm pool heat budget and shortwave cloud forcing: A missing physics? Science, 267, 499-503.

Reynolds, R. W., and T. M. Smith, 1994: Improved global sea surface temperature analysis using optimum interpolation. $J$. Climate, 7, 929-948.

Servain, J., A. J. Busalacchi, M. J. McPhaden, A. D. Moura, G. Reverdin, M. Vianna, and S. E. Zebiak, 1998: A pilot research moored array in the tropical Atlantic. Bull. Amer. Meteor. Soc., 79, 2019-2031.

Sheinbaum, J., J. Candela, A. Badan, and J. Ochoa, 2002: Flow structure and transport in the Yucatan Channel. Geophys. Res. Lett., 29, 1040, doi:10.1029/2001GL013990.

Teague, W. J., M. J. Carron, and P. J. Hogan, 1990: A comparison between the Generalized Digital Environmental Model and Levitus climatologies. J. Geophys. Res., 95 (C5), 7167-7183.

Toole, J. M., H.-M. Zhang, and M. J. Caruso, 2004: On the timedependent internal energy budgets of the tropical warmwater pools. J. Climate, 17, 1398-1410.

Virmani, J., and R. H. Weisberg, 2003: Features of observed annual ocean-atmosphere flux variability on the west Florida shelf. J. Climate, 16, 734-745.

Wang, C., and D. B. Enfield, 2001: The tropical Western Hemisphere warm pool. Geophys. Res. Lett., 28, 1635-1638.

—, and - 2003: A further study of the tropical Western Hemisphere warm pool. J. Climate, 16, 1476-1493.

Weisberg, R. H., 1996: On the evolution of SST over the PACS region. Preprints, Eighth Conf. on Air-Sea Interaction and Conf. on the Global Ocean-Atmosphere-Land System $(G O A L S)$, Atlanta, GA, Amer. Meteor. Soc., 378.

Woodruff, S. D., H. F. Diaz, J. D. Elms, and S. J. Worley, 1998: COADS release 2 data and metadata enhancements for improvements of marine surface flux fields. Phys. Chem. Earth, 23, 517-526. 